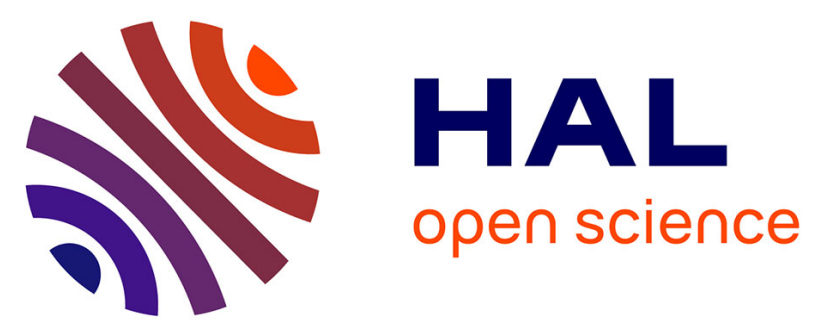

\title{
Seismic Wave Attenuation and Dispersion Due to Partial Fluid Saturation: Direct Measurements and Numerical Simulations Based on X-Ray CT
}

Samuel Chapman, Jan V. M. Borgomano, Beatriz Quintal, Sally M Benson, Jerome Fortin

\section{To cite this version:}

Samuel Chapman, Jan V. M. Borgomano, Beatriz Quintal, Sally M Benson, Jerome Fortin. Seismic Wave Attenuation and Dispersion Due to Partial Fluid Saturation: Direct Measurements and Numerical Simulations Based on X-Ray CT. Journal of Geophysical Research: Solid Earth, 2021, 10.1029/2021JB021643 . hal-03272869

\section{HAL Id: hal-03272869 \\ https://hal.science/hal-03272869}

Submitted on 28 Jun 2021

HAL is a multi-disciplinary open access archive for the deposit and dissemination of scientific research documents, whether they are published or not. The documents may come from teaching and research institutions in France or abroad, or from public or private research centers.
L'archive ouverte pluridisciplinaire HAL, est destinée au dépôt et à la diffusion de documents scientifiques de niveau recherche, publiés ou non, émanant des établissements d'enseignement et de recherche français ou étrangers, des laboratoires publics ou privés. 


\section{JGR Solid Earth}

\section{RESEARCH ARTICLE \\ 10.1029/2021JB021643 \\ Key Points: \\ - Measurements of seismic wave \\ Seismic Wave Attenuation and Dispersion Due to Partial Fluid Saturation: Direct Measurements and Numerical Simulations Based on X-Ray CT} attenuation and dispersion in a partially saturated sandstone

- Partial saturation was achieved by exsolution of carbon dioxide and was characterized with X-ray computed tomography

- Fluid distribution was used to numerically simulate attenuation and dispersion due to fluid pressure diffusion

Correspondence to:

S. Chapman,

samuel.chapman38@gmail.com

Citation:

Chapman, S., Borgomano, J. V. M., Quintal, B., Benson, S. M., \& Fortin, J. (2021). Seismic wave attenuation and dispersion due to partial fluid saturation: Direct measurements and numerical simulations based on X-ray CT. Journal of Geophysical Research: Solid Earth, 126, e2021JB021643. https://doi.org/10.1029/2021JB021643

Received 1 JAN 2021 Accepted 15 MAR 2021

(C) 2021. American Geophysical Union. All Rights Reserved.

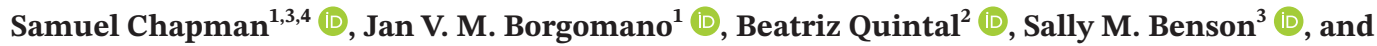 \\ Jérôme Fortin ${ }^{1}$ \\ ${ }^{1}$ Laboratoire de Géologie, Ecole Normale Supérieure/CNRS UMR 8538, PSL Research University, Paris, France, \\ ${ }^{2}$ Institute of Earth Sciences, University of Lausanne, Lausanne, Switzerland, ${ }^{3}$ Department of Energy Resources \\ Engineering, Stanford University, Stanford, CA, USA, ${ }^{4}$ Now at: Ecole Normale Supérieure, Paris, France
}

\begin{abstract}
Quantitatively assessing seismic attenuation caused by fluid pressure diffusion (FPD) in partially saturated rocks is challenging because of its sensitivity to the spatial fluid distribution. To address this challenge we performed depressurization experiments to induce the exsolution of carbon dioxide from water in a Berea sandstone sample. In a first set of experiments we used medical X-ray computed tomography (CT) to characterize the fluid distribution. At an equilibrium pressure of approximately $1 \mathrm{MPa}$ and applying a fluid pressure decline rate of approximately 0.6 MPa per minute, we allowed a change in saturation of less than $1 \%$. The gas was heterogeneously distributed along the length of the sample, with most of the gas exsolving near the sample outlet. In a second set of experiments, at the same pressure and temperature, following a very similar exsolution protocol, we measured the frequency dependent attenuation and modulus dispersion between 0.1 and 1,000 $\mathrm{Hz}$ using the forced oscillation method. We observed significant attenuation and dispersion in the extensional and bulk deformation modes, however, not in the shear mode. Lastly, we use the fluid distribution derived from the X-ray CT as an input for numerical simulations of FPD to compute the attenuation and modulus dispersion. The numerical solutions are in close agreement with the attenuation and modulus dispersion measured in the laboratory. Our approach allows for accurately relating attenuation and dispersion to the fluid distribution, which can be applied to improving the seismic monitoring of the subsurface.
\end{abstract}

\section{Introduction}

Seismic waves propagating through rocks saturated with multiple fluids can be attenuated by fluid pressure diffusion (FPD) because of the contrast in compressibility between the different fluid phases. The compression of the pore space by a seismic wave induces a pressure gradient and consequently pressure diffusion between the fluid phases of different compressibility. FPD is also referred to as patchy saturation or wave induced fluid flow (WIFF). Attenuation and the associated dispersion of seismic waves by FPD are sensitive to the saturation and spatial distribution of the fluids as well as the rocks permeability (Müller et al., 2010; Pride et al., 2004). These qualities make seismic methods particularly interesting for monitoring $\mathrm{CO}_{2}$ storage sites in order to characterize the extent of a plume and for probing how effectively a formation is trapping the $\mathrm{CO}_{2}$ (Caspari et al., 2011; Ivanova et al., 2012; Zhu et al., 2017). However, accurately relating the fluid distribution to the seismic properties of the formation remains challenging because systematic and accurate laboratory measurements of frequency dependent attenuation and dispersion are still rare.

There is a substantial theoretical basis for FPD as a significant source of seismic wave attenuation in rocks saturated with multiple fluid phases. White (1975) and White et al. (1975) derived the first simple analytical solutions for periodically alternating spherical patches or layers of fluids, respectively, in a homogenous and isotropic porous matrix, demonstrating the potential of significant P-wave attenuation and modulus dispersion at seismic frequencies. Further analytical solutions have been derived to account for similar or arbitrary fluid heterogeneities (e.g., Johnson, 2001; Kobayashi \& Mavko, 2016; Pride et al., 2004; Toms et al., 2007). FPD has also been studied by employing numerical methods to solve Biot's (1962) dynamic poroelastic equations (e.g., Carcione et al., 2003; Masson \& Pride, 2007; Rubino et al., 2009) and Biot's (1941) quasi-static consolidation equations (e.g., Quintal et al., 2011). Numerical simulations allow for modeling 
the response of complex heterogeneities and distributions in the saturating fluids as well as in the physical properties of the porous material.

Different methods are used to experimentally investigate the attenuation of seismic waves across a wide range of frequencies. At ultrasonic frequencies the attenuation of transmitted waves can be inferred from multiple reflections in the sample (e.g., Winkler \& Plona, 1982) or with the spectral ratio method (e.g., Toksöz et al., 1979). In the kilohertz range the resonant bar is a reliable method (e.g., Cadoret et al., 1998, 1995; Lucet et al., 1991; Murphy, 1982; Nakagawa, 2011; Winkler \& Nur, 1979). However, the drawback of these methods is that resolution with respect to frequency is poor and the probed frequency range is narrow. Wave attenuation and dispersion at seismic frequencies $(<500 \mathrm{~Hz})$ cannot be directly measured in the laboratory because the typical wavelength is far greater than the sample size. Instead the stress-strain response of samples is measured when applying a sinusoidal stress, also known as the forced oscillation method (e.g., McKavanagh \& Stacey, 1974). The attenuation is inferred from the phase shift between the stress and strain signals and the stiffness modulus of the rock is determined from their amplitudes. Current state of the art forced oscillation experimental set-ups can measure attenuation and modulus dispersion in the extensional mode, continuously from less than $1 \mathrm{~Hz}$ up to $100 \mathrm{~Hz}$, and in a few cases up to 1-2 kHz (e.g., Batzle et al., 2006; Borgomano et al., 2020; Nakagawa, 2013; Spencer, 1981; Tisato \& Madonna, 2012).

An important restriction in quantitatively assessing the attenuation and dispersion in partially saturated rocks is often a lack of knowledge of how the fluids are distributed in the pore space during experiments. Cadoret et al. $(1995 ; 1998)$ qualitatively assessed the changes in attenuation, measured in the kilohertz range, with respect to the fluid distribution observed with X-ray computed tomography (X-ray CT). Nakagawa et al. (2013) also used X-ray CT to visualize the fluid distribution from which they estimate the size of fluid patches as an input for White's (1975) analytical solution, observing discrepancies between the analytical solution and the experimental measurements of attenuation and dispersion at $1 \mathrm{kHz}$. Toms-Stewart et al. (2009) developed a statistical methodology to quantify the distribution of fluid phases from X-ray CT slices and use this information as an input for their analytical model of attenuation and dispersion. Qi et al. (2014) extend the work by Toms et al. (2007) and Toms-Stewart et al. (2009) to include the impact of interfacial tension on FPD and analyze the attenuation and velocity dispersion of ultrasonic wave measurements from core flooding experiments with concurrent X-ray CT (Lopes et al., 2014; Lopes \& Lebedev, 2012). Kobayashi and Mavko (2016) also extend the approach of Toms-Stewart et al. (2009) and use the X-ray CT data and attenuation measured by Cadoret et al. $(1995 ; 1998)$ to validate their approach. Both Qi et al. (2014) and Kobayashi and Mavko (2016) calibrate their approaches to fit the experimental observations. In the seismic frequency range Tisato and Quintal (2013) measured the extensional mode attenuation and Young's modulus dispersion in a partially saturated Berea sandstone sample. From the fluid pressure response measured along the length of the sample, they inferred an approximate fluid distribution which they use to construct a numerical model to simulate the frequency dependent attenuation and dispersion, as well as the time dependent fluid pressure diffusion.

Previous studies investigating the relationships between water saturation and seismic wave velocity and attenuation using X-Ray CT have focused primarily on imbibition and drainage scenarios (e.g., Alemu et al., 2013; Nakagawa et al., 2013; Zhang et al., 2015). However, multiple fluid phases can also be introduced into porous materials by allowing dissolved gasses to come out of solution from the saturating liquid. Changes in the time-lapse attenuation of seismic waves in reservoirs have been associated with the exsolution of gas due to production induced pressure reduction (Blanchard \& Delommot, 2015; Falahat et al., 2014). In the laboratory, Johnston and Toksöz (1980) measured P- and S-wave velocities and attenuation at ultrasonic frequencies in a Berea sandstone following the exsolution of helium gas. The release of gas was induced by reducing the pore pressure from 12 to $1.5 \mathrm{MPa}$, while maintaining a constant differential stress. Between $0 \%$ and $5 \%$ gas saturation the measured P-wave velocity is significantly reduced, while the S-wave velocity and the attenuation of both P- and S-waves showed no statistically significant change. At seismic frequencies significant frequency dependent attenuation and dispersion have been observed following the exsolution of gas at pore pressures of less than $1 \mathrm{MPa}$ (Chapman et al., 2017; Tisato et al., 2015) and at 2.4 MPa (Spencer \& Shine, 2016) in Berea sandstone samples. However, none of these studies had the ability to assess the fluid distribution during the experiments and assumed the gas bubbles 
were homogeneously distributed (Chapman et al., 2017; Johnston \& Toksöz, 1980; Tisato et al., 2015), which makes it challenging to assess the physical process responsible for the observed attenuation and dispersion.

At reservoir conditions up to $5 \%$ of the $\mathrm{CO}_{2}$ mass fraction can dissolve into reservoir brines, depending on pressure, temperature, and brine composition (Duan \& Sun, 2003). This makes solubility trapping an important mechanism (Benson \& Cole, 2008) for safely storing $\mathrm{CO}_{2}$ in subsurface formations. Dissolved $\mathrm{CO}_{2}$, however, can come out of solution when pore pressures are reduced, either by withdrawing fluids (Zuo et al., 2012, 2013) or reducing the confining pressure under undrained conditions (Crews \& Cooper, 2014), or the temperature is increased (Luhmann et al., 2012). Depressurization can occur when brines invade shallower formations by leaking through faults or when the stress on a formation is reduced by seismicity (Allman \& Shearer, 2007; Goertz-Allmann et al., 2011; Stabile et al., 2012). Using X-Ray CT Zuo et al. (2012) observe a homogenous distribution of the exsolved $\mathrm{CO}_{2}$ at pore pressures between 12.41 and 2.76 MPa and $50^{\circ} \mathrm{C}$ and find no statistical correlation between porosity and $\mathrm{CO}_{2}$ saturation. Importantly, relative permeabilities are significantly different to drainage experiments and residual trapping is significantly higher following exsolution (Zuo \& Benson, 2014; Zuo et al., 2012). How gas is distributed in the pore space is dependent on the fluid properties and the rates at which the pore pressure is reduced (Li \& Yortsos, 1995) and a homogenous gas distribution at pore pressures $<1 \mathrm{MPa}$, as assumed by previous studies may not be accurate.

On a single Berea sandstone sample we performed $\mathrm{CO}_{2}$ exsolution experiments in separate experimental setups to (i) visualize the fluid distribution and (ii) measure the frequency dependent attenuation and modulus dispersion. We subsequently developed a workflow to incorporate the fluid saturation distribution, determined with the X-ray CT, into our numerical implementation of Biot's (1941) consolidation equations to simulate the attenuation and modulus dispersion caused by FPD. The following sections will present the laboratory set-ups and methodologies used, the experimental procedures followed to induce the $\mathrm{CO}_{2}$ exsolution and the experimental results pertaining to the imaging of the fluid distribution and frequency-dependent attenuation and dispersion. Following the discussion of the experimental observations we will cover the numerical methodology and compare the numerical solutions to the attenuation and dispersion measured in the laboratory. Finally, we will briefly discuss the next steps to be taken to extent our workflow to incorporate additional properties of samples that can be determined in combination with X-ray CT.

\section{Experimental Methodology}

\subsection{Equipment and Methodology}

Two separate set-ups were used to conduct the $\mathrm{CO}_{2}$ exsolution experiments. A first set of experiments were conducted at Stanford University to measure the samples porosity and $\mathrm{CO}_{2}$ saturation distribution (Figure 1a). A second set of experiments were conducted at ENS Paris to measure the samples frequency dependent attenuation $\left(\mathrm{Q}^{-1}\right)$ and modulus dispersion (Figure $\left.1 \mathrm{~b}\right)$.

\subsubsection{Porosity and $\mathrm{CO}_{2}$ Saturation}

To measure the samples porosity and $\mathrm{CO}_{2}$ saturation distribution in the first set-up, experiments were carried out in a coreflooding set-up using a medical X-ray computed tomography scanner (General Electric Hi-Speed X-ray CT). The main components of the set-up (Figure 1a) are five syringe pumps (Teledyne Isco, model 500D and 1000D) for circulating fluids in a closed loop, with an integrated two-phase separator and a low X-ray absorbing aluminum pressure vessel housing the sample. A detailed description of the setup can be found in Krevor et al. (2012).

The scanning of the sample is performed at a tube current of $200 \mathrm{~mA}$ and a radiation energy level of $120 \mathrm{keV}$. With a field of view of $9.6 \mathrm{~cm}$ the initial pixel resolution is $0.1875 \times 0.1875 \mathrm{~mm}^{2}$, which in the processing of the images is coarsened to $1.5 \times 1.5 \mathrm{~mm}^{2}$. Scans are taken at $1.25 \mathrm{~mm}$ intervals giving a voxel resolution of $1.5 \times 1.5 \times 1.25 \mathrm{~mm}^{3}$. Scans of the entire sample can be taken within 3-4 min. Coarsening is performed to achieve a representative elementary volume (REV) in which porosity and $\mathrm{CO}_{2}$ saturation are determined, but also to reduce the error in these properties. The error in the voxel scale porosity and $\mathrm{CO}_{2}$ saturation is further reduced by performing the analysis on the average of three repeated scans. The error 
a)
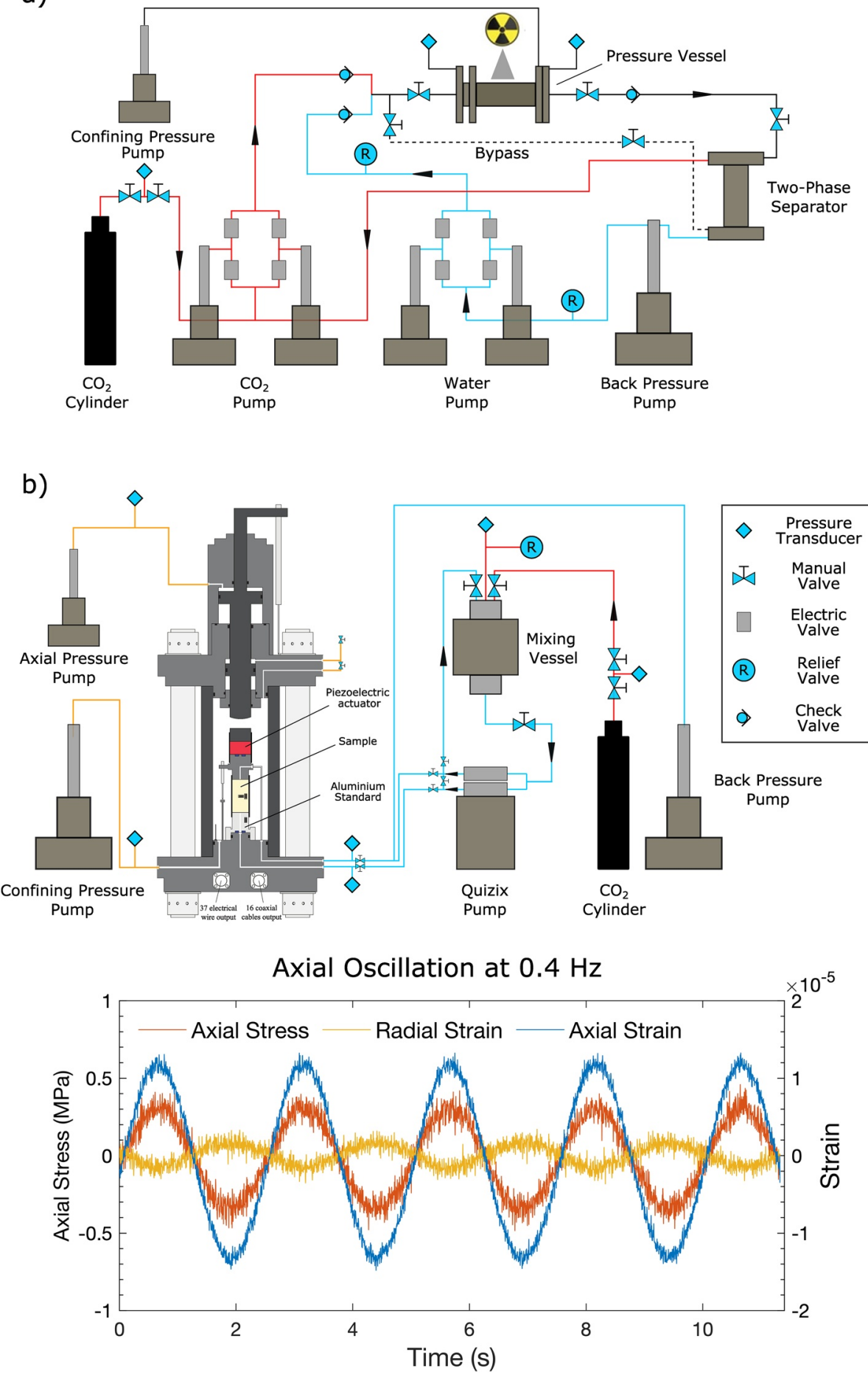

Figure 1. Schematic illustration of (a) the set-up used for the characterization of porosity and fluid distribution, adapted from Zuo et al. (2012), and (b) the tri-axial cell used for the forced oscillation measurements, adapted from Borgomano et al. (2020), with an example of the applied axial stress and measured axial and radial strains on a dry Berea sandstone sample at $0.4 \mathrm{~Hz}$. 
in porosity and $\mathrm{CO}_{2}$ saturation at the voxel and slice scale is determined following the procedure laid out by Pini et al. (2012).

The X-ray saturation technique is used to determine the voxel scale porosity and $\mathrm{CO}_{2}$ saturation, by combining scans of the sample saturated with different fluids (e.g., Akin \& Kovscek, 2003). The porosity $\phi$ is determined in the following way:

$$
\phi=\frac{\mathrm{CT}_{\mathrm{WR}}-\mathrm{CT}_{\mathrm{AR}}}{\mathrm{CT}_{\mathrm{W}}-\mathrm{CT}_{\mathrm{A}}},
$$

where $\mathrm{CT}_{\mathrm{WR}}$ and $\mathrm{CT}_{\mathrm{AR}}$ are the $\mathrm{CT}$ numbers in Hounsfield units (HU) of the fully water and air saturated sample, respectively. $\mathrm{CT}_{\mathrm{W}}=0$ and $\mathrm{CT}_{\mathrm{A}}=-983$ are the $\mathrm{CT}$ numbers of water and air, respectively. The CT number of water was measured separately on a phantom sample and the CT number of air was measured on a portion of the scan outside of the pressure vessel.

The $\mathrm{CO}_{2}$ saturation $\mathrm{S}_{\mathrm{CO}_{2}}$ is determined in the following way:

$$
\mathrm{S}_{\mathrm{CO}_{2}}=\frac{\mathrm{CT}_{\mathrm{SolR}}-\mathrm{CT}_{\mathrm{ExpR}}}{\mathrm{CT}_{\mathrm{SolR}}-\mathrm{CT}_{\mathrm{CO}_{2} \mathrm{R}}},
$$

where $\mathrm{CT}_{\text {SolR }}$ is the $\mathrm{CT}$ number of the sample saturated with $\mathrm{CO}_{2}$-equilibrated water, $\mathrm{CT}_{\operatorname{ExpR}}$ is the $\mathrm{CT}$ number of the sample scanned during the experiment and $\mathrm{CT}_{\mathrm{CO}_{2} \mathrm{R}}$ is the $\mathrm{CT}$ number of the sample saturated fully with $\mathrm{CO}_{2}$. The background scans of the $\mathrm{CO}_{2}$ saturated sample were performed at the same or comparable pore and confining pressures as the scans from the experiment. Visualisation of porosity and saturation distributions was carried out in Matlab, for the 3D figures the plotting function vol3D by Woodford (2020) was used.

\subsubsection{Forced Oscillation}

The sample's frequency dependent attenuation $\left(\mathrm{Q}^{-1}\right)$ and modulus dispersion are measured in the second setup by employing the forced oscillation method (e.g., McKavanagh \& Stacey, 1974) in a tri-axial cell (TOP Industrie) (Figure 1b). Axial stress oscillations are applied to the sample by a multilayered piezoelectric actuator, allowing for stress oscillations of up to 1,000 Hz. Axial and radial strains on the sample (approximately $10^{-5}$ to $10^{-6}$ ) are measured with four bi-axial $350 \Omega$ foil gauges (TML FCB-6-350-11) that have a length of $6 \mathrm{~mm}$, while the axial stress is determined from the elastic deformation of the aluminum end plate. At low frequencies $(<1 \mathrm{~Hz})$ stress and strains are averaged over a minimum of 50 cycles, which are successively increased up to 1,200 cycles per frequency for frequencies $>1 \mathrm{~Hz}$. The sampling rate is typically 20 times higher than the frequency of the stress oscillation. The amplitude and phase angles are determined from Fourier transforms of the averaged signals of the axial and radial strains. A detailed description of the forced oscillation set-up, data processing, and calibration can be found in Borgomano et al. (2020).

From the axial stress oscillations, the sample's Poisson ratio $\nu$ and Young's modulus $E$ can be determined in the following way:

$$
v=-\frac{\epsilon_{\mathrm{rad}}}{\epsilon_{\mathrm{ax}}} \text { and } E=\frac{\sigma_{\mathrm{ax}}}{\epsilon_{\mathrm{ax}}}
$$

where $\epsilon_{\mathrm{ax}}$ and $\epsilon_{\mathrm{rad}}$ are the measured axial and radial strains, respectively, and $\sigma_{\mathrm{ax}}$ is the axial stress. Assuming the sample is elastically isotropic, the bulk $K$ and shear $G$ modulus can be inferred as follows:

$$
K=\frac{E}{3(1-2 v)} \quad \text { and } \quad G=\frac{E}{2(1+v)}
$$




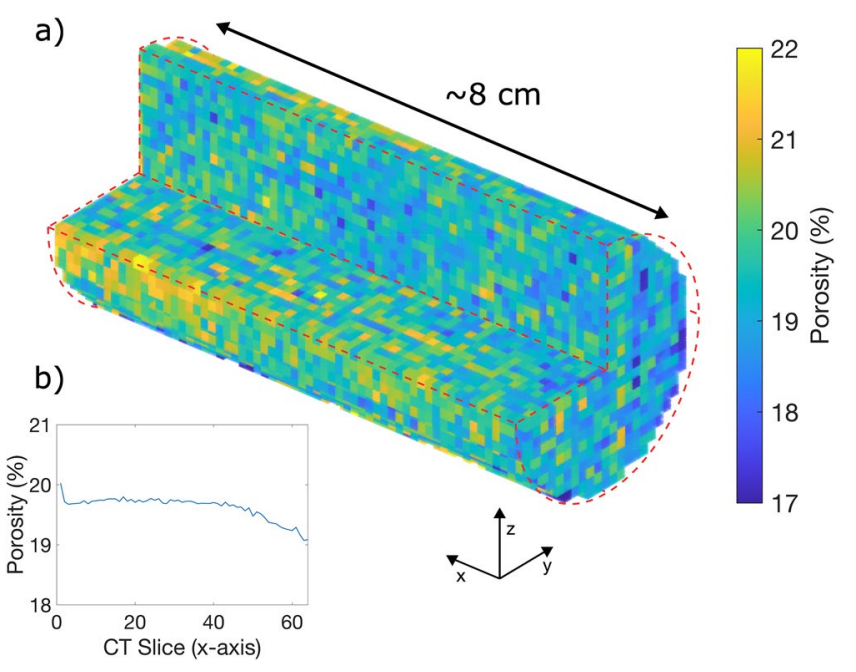

Figure 2. (a) 3D porosity distribution and (b) slice averaged porosity for sample BSP4. The porosity is reconstructed from the dry and water saturated medical X-Ray computed tomography scans. Scans taken along $x$-axis. The voxel dimensions are $(1.5 \times 1.5 \times 1.25) \mathrm{mm}^{3}$ and the precision in porosity is $\pm 0.6 \%$ abs. CT Slice 0 corresponds to the outlet side of the sample, facing the back pressure pump of Figure 1a.
The associated attenuation for each mode of deformation can be determined from the phase shift $\Delta \phi$ between the stress and strain oscillations, which is also related to the imaginary and real parts of the respective complex modulus $M$ of the solid (O'Connell and Budiansky, 1978):

$$
Q^{-1}=\tan (\Delta \phi)=\frac{\operatorname{Im}(M)}{\operatorname{Re}(M)} .
$$

In the extensional mode the phase shift is defined as:

$$
\Delta \phi_{\text {extensional }}=\phi_{\sigma_{\mathrm{ax}}}-\phi_{\epsilon_{\mathrm{ax}}},
$$

where $\phi_{\sigma_{\mathrm{ax}}}$ and $\phi_{\epsilon_{\mathrm{ax}}}$ are the phase angles of axial stress and strain, respectively. In a similar fashion the phase shift for the bulk and shear mode deformations can be inferred from the axial stress and axial and radial strains (Borgomano et al., 2017):

$$
\Delta \phi_{\text {bulk }}=\phi_{\sigma_{\mathrm{ax}}}-\phi_{\epsilon_{\mathrm{ax}}+2 \epsilon_{\mathrm{rad}}} \text { and } \Delta \phi_{\text {shear }}=\phi_{\sigma_{\mathrm{ax}}}-\phi_{\epsilon_{\mathrm{ax}}-\epsilon_{\mathrm{rad}}},
$$

where the phase angles of the strains $\left(\epsilon_{\mathrm{ax}}+2 \epsilon_{\mathrm{rad}}\right)$ and $\left(\epsilon_{\mathrm{ax}}-\epsilon_{\mathrm{rad}}\right)$ are derived from combinations of Equations 3 and 4.

The tri-axial cell is connected to a pore fluid circuit (Figure 1b) composed of a mixing vessel (TOP Industrie), a Quizix pump (Chandler Engineering, model QX6000) and a syringe pump (TOP Industrie). The mixing vessel and Quizix pump are configured in a closed loop, directly connected to the $\mathrm{CO}_{2}$ cylinder. Hydraulically activated micro-valves, embedded in the top and bottom sample holders, reduce the remaining volume of the fluid lines connected to the sample to approximately 30 micro liters. The ratio of the remaining volume of the fluid lines to the pore volume of the sample is approximately $1 \times 10^{-3}$, allowing for conducting forced oscillation measurements under effectively un-drained conditions.

\subsection{Sample Description and Preparation}

The sample (BSP4) used in this study was cored from the same block of Berea sandstone as the sample used by Chapman et al. (2019), which was purchased from Cleveland Quarries (Vermillion, Ohio, USA). The samples permeability for deionized water at approximately 9 MPa differential pressure (difference between the confining and pore pressure) is $271 \pm 3.5 \mathrm{mD}$ and was determined by applying five flow rates between 1 and $20 \mathrm{ml}$ per minute and measuring the pressure gradient between the inlet and outlet. The porosity determined with a pyknometer on a sample from the same block was 22.1\% (Chapman et al., 2019). An extensive characterization of Berea sandstone samples from Cleveland Quarries by Kareem et al. (2017) shows Quartz to be the dominant mineral (approximately 80\%-95\%). The remaining minerals are Feldspar and various clays (3\%-8\%), with clays being over-represented at pore surfaces according to Kareem et al. (2017). Scanning electron microscopy and energy dispersion spectrometry (SEM-EDS) analyses on a sample taken from the same block as BSP4 (Figure 2 in Chapman et al., 2019) show large quantities of quartz, with smaller amounts feldspar and clays, consistent with the analysis of Kareem et al. (2017). Figure 2 shows the 3D and slice averaged porosity, reconstructed from the X-ray CT. While there is some faint layering parallel to the $x$-axis the porosity is approximately constant along the length of the sample (Figure $2 \mathrm{~b}$ ) and the average porosity is $19.6 \%$.

The sample was cored to a diameter of $4 \mathrm{~cm}$ and cut to a length of $8 \mathrm{~cm}$. Fixed in a cylindrical steel holder and mounted on a lathe, the sample ends were machined parallel to each other with a diamond-studded grinder. The sample was dried in an oven $\left(60-70^{\circ} \mathrm{C}\right)$ for several days before mounting in the experimental set-ups. For the forced oscillation measurements, four strain gauge pairs were attached at $90^{\circ}$ intervals, centered on the sample's lateral surface. To avoid the failure of the strain gauges when applying elevated confining pressures, patches on the sample's surface were prepared with a thin layer of resin that were polished down to the grains. To prevent corrosion from the carbonated water, the strain gauges and wires were sealed 
Journal of Geophysical Research:Solid Earth

Table 1

Overview of Experiments

\begin{tabular}{|c|c|c|c|c|c|c|c|}
\hline Measurement & $\begin{array}{l}\text { Experiment } \\
\text { ID }\end{array}$ & $\begin{array}{l}\text { Initial confining } \\
\text { pressure }(\mathrm{MPa})\end{array}$ & $\begin{array}{l}\text { Final confining } \\
\text { pressure }(\mathrm{MPa})\end{array}$ & $\begin{array}{c}\text { Initial pore } \\
\text { pressure (MPa) }\end{array}$ & $\begin{array}{c}\text { Final pore } \\
\text { pressure (MPa) }\end{array}$ & $\begin{array}{l}\text { Pressure decline } \\
\text { rate }(\mathrm{MPa} / \mathrm{min})\end{array}$ & $\begin{array}{l}\text { Mode of } \\
\text { pressure decline }\end{array}$ \\
\hline \multirow[t]{3}{*}{ Medical X-Ray CT } & Exs-8b & 10 & 10 & 1.1 & 0.95 & $\sim 0.6$ & Back Pressure \\
\hline & Exs-9 & 10 & 10 & 1.1 & 0.95 & $\sim 0.6$ & Back Pressure \\
\hline & Exs-10b & 10 & 10 & 1.1 & 0.95 & $\sim 0.6$ & Back Pressure \\
\hline \multirow[t]{3}{*}{ Forced Oscillation } & Exs-2 & 10.5 & 10.5 & 1.1 & 0.9 & 6.5 & Back Pressure \\
\hline & Exs-3 & 15 & 11 & 1.5 & $\sim 1^{\mathrm{a}}$ & 6.5 & Hydrostatic \\
\hline & Exs-4 & 15 & 11 & 1.5 & $\sim 1^{\mathrm{a}}$ & 0.02 & Hydrostatic \\
\hline
\end{tabular}

${ }^{a}$ Inferred after opening micro-valves following completion of the experiment.

in a thin layer of soft epoxy. The sample was placed in a rubber jacket, with epoxy sealed feed-throughs for the wires connecting to the strain gauges, isolating the sample from the confining oil. In addition the outside of the rubber jacket was covered in aluminum foil to prevent diffusion of carbon dioxide from the sample into the confining oil.

\subsection{Experimental Procedure- $\mathrm{CO}_{2}$ Exsolution}

The $\mathrm{CO}_{2}$ saturated water was prepared by dissolving $\mathrm{CO}_{2}$ in deionized (DI) water at room temperature and a pressure of $1 \mathrm{MPa}$. At these conditions the mole fraction of $\mathrm{CO}_{2}$ dissolved in the water is on the order of $0.6 \%$ (mass fraction of 1.5\%) (Duan \& Sun, 2003). For the set-up at Stanford University (Figure 1a), the two pairs of syringe pumps circulated $\mathrm{CO}_{2}$ and water through the fluid circuit via the bypass and two-phase separator, with the back pressure pump regulating the pressure in the system. Equilibrium is expected to have been reached when the $\mathrm{CO}_{2}$-water interface in the two phase separator stopped moving. For the set-up at ENS Paris (Figure 1b) the Quizix pump circulated water through the mixing vessel, by drawing water from the bottom and re-injecting it into the top of the vessel. The pressure in the system was regulated from the $\mathrm{CO}_{2}$ cylinder. For both set-ups, at least $24 \mathrm{~h}$ were allowed for the mixing of the $\mathrm{CO}_{2}$ and water, with the pressure being monitored by transducers in the pumps and an analog pressure sensor attached to the mixing vessel. In both setups the temperature in the pressure vessels was monitored with a thermocouple.

To fully saturate the sample with water, the dry sample was first flushed with $\mathrm{CO}_{2}$, to remove the air from the pore space. DI water was then injected into the sample and the fluid pressure raised above $1 \mathrm{MPa}$ to dissolve the $\mathrm{CO}_{2}$ and fully saturate the sample. Multiple pore-volumes of DI water were subsequently flushed through the sample. $\mathrm{CO}_{2}$ saturated water was then injected into the sample at a fluid pressure greater than 1.2 $\mathrm{MPa}$ and flow rates of 2-4 $\mathrm{ml}$ per minute. To ensure all of the DI water had been replaced by $\mathrm{CO}_{2}$ saturated water, up to 10 pore volumes were flushed through the sample.

The exsolution of $\mathrm{CO}_{2}$ in the pore space of the sample was induced by reducing the fluid pressure below the equilibrium pressure of $1 \mathrm{MPa}$. Two methods were employed to reduce the pore fluid pressure: (i) increasing the system volume by a fixed amount using a pore fluid pump and (ii) hydrostatically reducing the confining pressure while the sample was undrained and allowing the pore volume to increase (Crews \& Cooper, 2014; Skempton, 1954). For the first method the back pressure pump and Quizix pumps were used to adjust the system volume, for the respective experimental set-ups, by withdrawing pore fluid from one side of the sample. Following the drop in fluid pressure the outlet valves were closed and the pressure was allowed to re-equilibrate. For the second method the confining pressure on the sample was reduced from 15 to $11 \mathrm{MPa}$, with the micro-valves in the sample holders closed. For the experiments with the X-ray CT only the first method was employed because it was not possible to hydrostatically reduce the confining pressure. Between experiments the pore fluid pressure was increased above $1 \mathrm{MPa}$ to re-dissolve the $\mathrm{CO}_{2}$ and then multiple pore-volumes of $\mathrm{CO}_{2}$ equilibrated water were flushed through the sample.

Table 1 provides an overview of the experiments conducted with the two set-ups. The three experiments performed with X-Ray CT are identical, with an initial fluid pressure of $1.1 \mathrm{MPa}$ and a pressure decline rate 

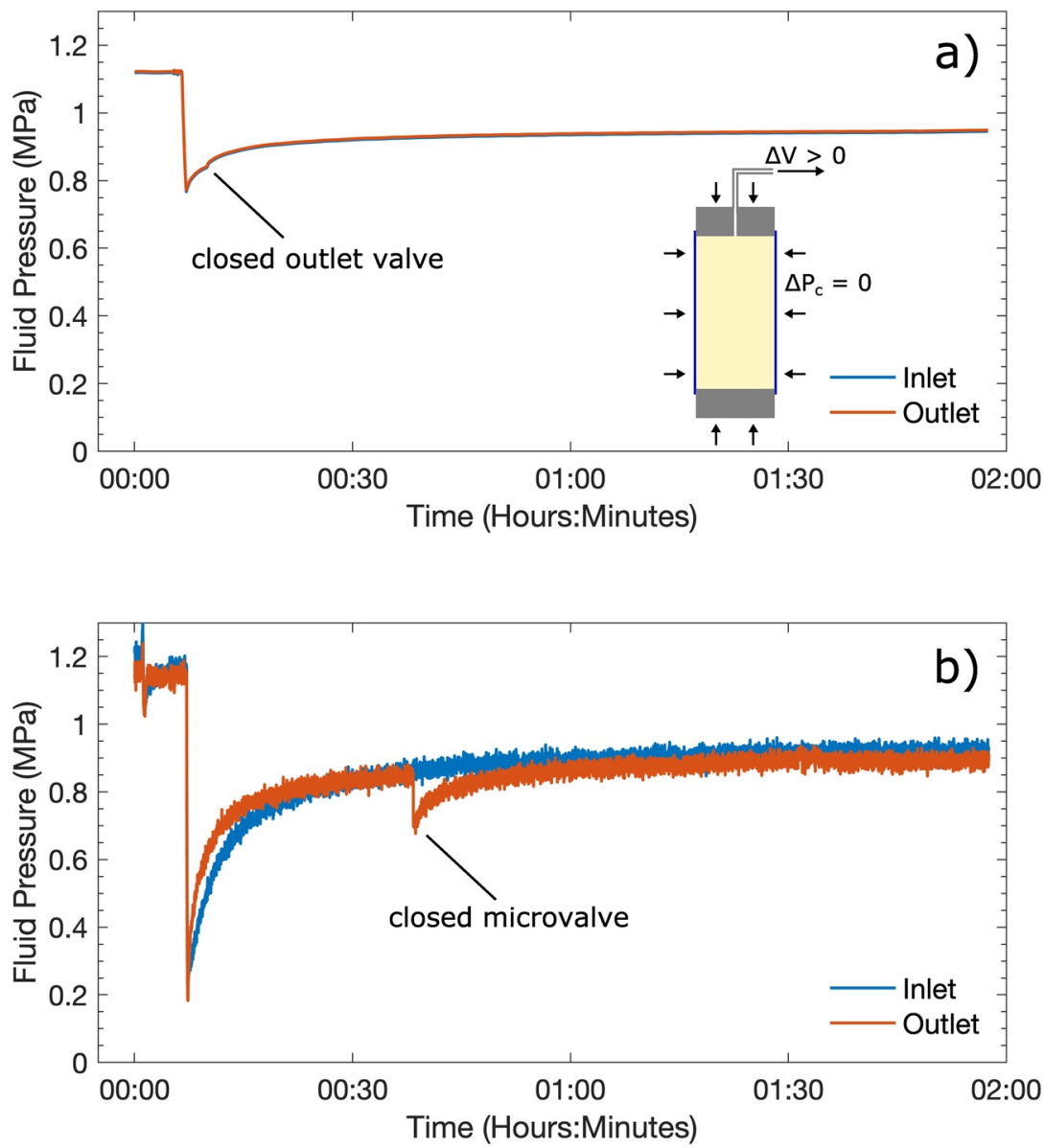

Figure 3. Fluid pressure response measured during the first $2 \mathrm{~h}$ of experiments (a) Exs-8b and (b) Exs-2. The inset shows how, for both experiments, the pressure in the sample was reduced using the back pressure pump. The fluid pressure was measured at the inlet and outlet.

of 0.6 MPa per minute. A similar experiment was performed with the tri-axial cell, however, with a pressure decline rate of 6.5 MPa per minute. For experiments Exs-3 and Exs-4 the initial fluid pressure, before closing the micro-valves, was approximately $1.5 \mathrm{MPa}$ and the confining pressure was reduced at a rate of 6.5 and 0.02 MPa per minute, respectively. The temperature during the experiments with the X-Ray CT was approximately $21^{\circ} \mathrm{C}\left( \pm 1^{\circ} \mathrm{C}\right)$ while the temperature during the experiments in the tri-axial cell was $24,22.7$, and $22.5^{\circ} \mathrm{C}\left( \pm 0.5^{\circ} \mathrm{C}\right)$ for Exs-2, Exs-3, and Exs-4, respectively. This variation in temperature reduces the solubility of $\mathrm{CO}_{2}$ between experiments conducted with the X-ray CT and Exs-2 by approximately 8\% (Duan \& Sun, 2003). It is important to note, however, that this difference in temperature has a negligible impact on the bulk moduli and viscosity of the fluids. At these pore pressures and temperatures the $\mathrm{CO}_{2}$ remains a gas when out of solution.

\section{Experimental Observations and Discussion}

\subsection{Fluid Distribution}

Figure 3 shows the fluid pressure in the sample following the increase in the system volume using the back pressure pump during the first $2 \mathrm{~h}$ of experiments Exs-8b (Figure 3a) and Exs-2 (Figure 3b). The increase in the system volume results in an initial drop of the fluid pressure below the equilibrium pressure of $1 \mathrm{MPa}$, because of the low compressibility of the water and the diffusive nature of the $\mathrm{CO}_{2}$ exsolution. As the $\mathrm{CO}_{2}$ comes out of solution the fluid pressure in the sample increases again and stabilizes after approximately $2 \mathrm{~h}$. 
a) Exs-9

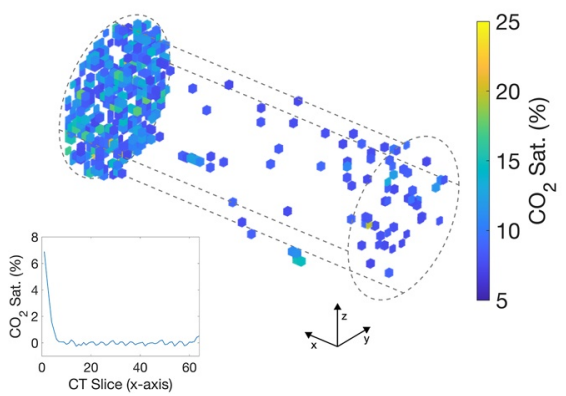

b) Exs-10b

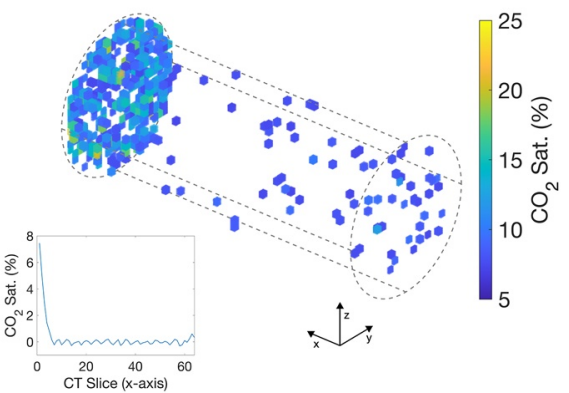

c) Exs-8b

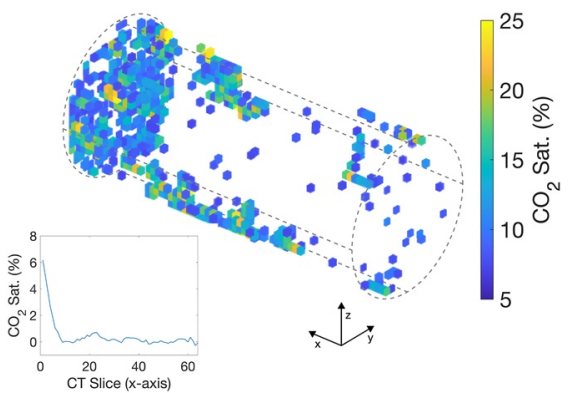

Figure 4. 3D and slice average $\mathrm{CO}_{2}$ saturation distribution in sample BSP4 for experiments (a) Exs-9, (b) Exs-10b, and (c) Exs-8b. Scans were taken approximately 3, 2.5, and $14 \mathrm{~h}$ after depressurization, for (a), (b), and (c), respectively. The mean saturation is approximately $0.3 \%$ for (a) and (b) and approximately $0.5 \%$ for (c). The voxel dimensions are $(1.5 \times 1.5 \times 1.25) \mathrm{mm}^{3}$ with a precision in saturation of $\pm 3.6 \%$ abs. Saturation values below $7.3 \%$ are set to zero and therefore appear transparent. CT Slice 0 corresponds to the outlet side of the sample, facing the back pressure pump of Figure 1a.

The rebound in pressure is consistent with pervious studies investigating the exsolution of $\mathrm{CO}_{2}$ in porous rocks (Crews \& Cooper, 2014).

Figure 4 shows the 3D and slice average $\mathrm{CO}_{2}$ distribution, reconstructed from the X-ray CT, for experiments Exs-8b, Exs-9, and Exs-10b. For the three experiments, the system volume was increased by the same amount and at the same rate to achieve a mean $\mathrm{CO}_{2}$ saturation in the sample that was less than $1 \%$. In all of the experiments the $\mathrm{CO}_{2}$ is heterogeneously distributed, with most of the $\mathrm{CO}_{2}$ accumulating near the outlet from which the depressurization was initiated. The scans for Exs-9 (Figure 4a) and Exs-10b (Figure 4b) were taken approximately 3 and $2.5 \mathrm{~h}$ after depressurization, at which point the mean $\mathrm{CO}_{2}$ saturation in the sample was $0.3 \%$. The scans for Exs- $8 \mathrm{~b}$ (Figure $4 \mathrm{c}$ ) were taken approximately $14 \mathrm{~h}$ after depressurization, at which point the mean $\mathrm{CO}_{2}$ saturation in the sample was slightly higher at $0.5 \%$. In the time span between $2 \mathrm{~h}$ after depressurization and scanning, the fluid pressure in the sample varied by less than $0.01 \mathrm{MPa}$, while the temperature dropped by about $1^{\circ} \mathrm{C}$. The $\mathrm{CO}_{2}$ distribution is more homogenous than for Exs- 9 and Exs$10 \mathrm{~b}$, with more $\mathrm{CO}_{2}$ having come out of solution further inside the sample.

The heterogenous distribution of $\mathrm{CO}_{2}$ along the length of the sample can be explained by the theory governing the nucleation and growth of the gas phase and has also been observed in previous experiments. Withdrawing fluid from one side of the sample establishes a pressure gradient across the sample and consequently a greater supersaturation, the difference between the pressure at which the water and $\mathrm{CO}_{2}$ were in equilibrium and the actual pore pressure, at the sample outlet and a preferential nucleation of gas there. Mechanistic modeling of solution gas drive in oils predicts a preferential exsolution of gas at the sample outlet (Arora \& Kovscek, 2003). Zuo et al. (2012) observe $\mathrm{CO}_{2}$ saturation gradients in a homogenous Berea sandstone after depressurization, when applying comparable pressure decline rates. The experiments of Zuo et al. (2012), however, were performed at significantly higher pressure and temperature conditions, as well as larger steps in pressure, resulting in overall higher $\mathrm{CO}_{2}$ saturations and smoother gradients in saturation along the length of the sample.

\subsection{Forced Oscillation-Partial Saturation}

Before conducting the forced oscillation measurements the dry sample was subjected to three hydrostatic confining pressure loading cycles from 3 to $20 \mathrm{MPa}$. From the hydrostatic loading we also determined an difference between the axial and radial strain, at $10 \mathrm{MPa}$ differential stress, of between $3 \%$ and $6 \%$. This introduces a small error when we assume mechanical isotropy as described in Section 2.1.2. Preliminary forced oscillation measurements were performed on the dry and water saturated sample at a differential pressure of $10 \mathrm{MPa}$. The measurements of the water saturated sample were conducted under drained and undrained conditions. The results of these measurements are found in Appendix A. 

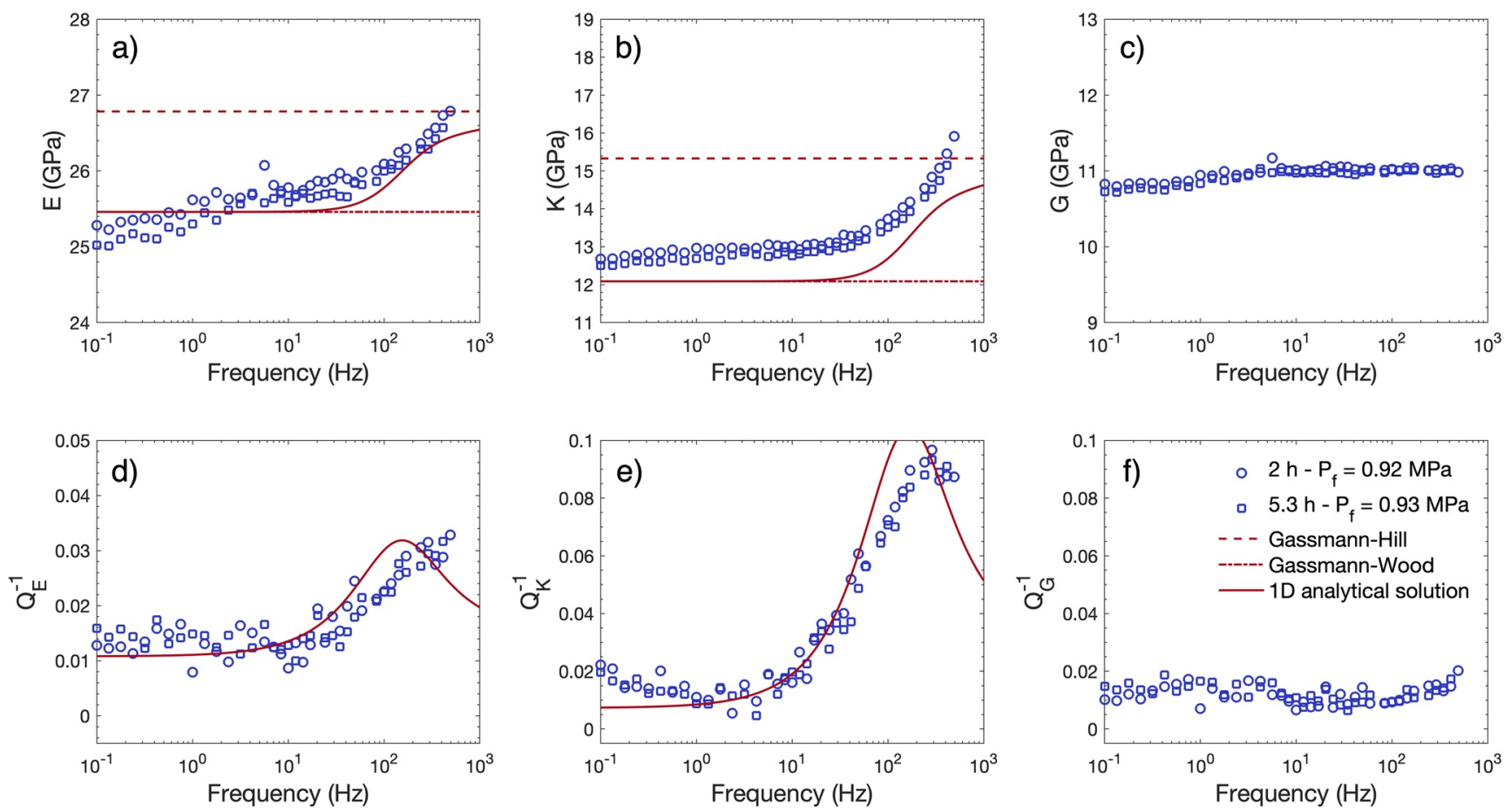

Figure 5. (a) Young's $E$, (b) Bulk $K$, and (c) Shear $G$ modulus and the corresponding attenuation (d) $Q_{E}^{-1}$, (e) $Q_{K}^{-1}$, and (f) $Q_{G}^{-1}$ from experiment Exs-2 measured at a differential pressure of approximately $9.5 \mathrm{MPa}$ and approximately $0.5 \% \mathrm{CO}_{2}$ saturation. The legend shows the time at which each measurement was taken after the initiation of depressurization, as well as the theoretical high and low frequency limits. Included in the figure is also the 1D analytical solution for the interlayer flow model (White et al., 1975).

\subsubsection{Depressurization-Back Pressure Pump}

In experiment Exs-2, the Quizix pump was used to increase the system volume by approximately $0.5 \%$ at a pressure decline rate of $6.5 \mathrm{MPa}$ per minute. Figure $3 \mathrm{~b}$ shows the fluid pressure measured at the inlet and outlet sides of the sample during the first $2 \mathrm{~h}$ of the experiment. During this experiment a micro-valve system configured as a check valve had been placed in the sample holders. The micro-valves allowed flow into the sample, but not out. To allow flow out of the sample the micro-valves can be propped open with a hydraulically activated pin. At the start of the experiment the inlet micro-valve was in a closed configuration and the outlet micro-valve propped open. At approximately $40 \mathrm{~min}$ into the experiment the outlet micro-valve was closed, resulting in a pressure drop on the outlet side of the sample. However, the pressure on the inlet side remained constant, indicating that there was little or no change of the pressure in the sample itself in response to closing the outlet micro-valve.

Figure 5 shows the results of two forced oscillation measurements taken during experiment Exs-2. The measurements were taken 2 and $5.3 \mathrm{~h}$ after depressurization and show strong dispersion in the Young's (Figure 5a) and Bulk moduli (Figure 5b), with corresponding frequency-dependent attenuation and an attenuation peak at 300-400 Hz (Figures $5 \mathrm{~d}$ and 5e). The shear modulus and attenuation are approximately frequency independent and negligible, respectively (Figures $5 \mathrm{c}$ and $5 \mathrm{f}$ ). The bulk modulus measured in the drained sample can be related to the bulk modulus of the undrained sample by using Gassmann's (1951) equation:

$$
K_{u}=K_{d}+\frac{\left(1-K_{d} / K_{s}\right)^{2}}{\phi / K_{f}+(1-\phi) / K_{s}-K_{d} / K_{s}^{2}},
$$

where $\phi$ is the porosity and $K_{u}, K_{d}, K_{s}$ and $K_{f}$ are the bulk moduli of the undrained sample, the drained sample, the solid matrix, and the pore fluid, respectively. Gassmann's (1951) equation assumes the rock is isotropic, monomineralic and that the pore fluid does not chemically interact with the minerals (e.g., 
Berryman, 1999). Furthermore, the derivation of Gassmann's (1951) relations shows that the shear modulus in the drained sample is the same as for the undrained sample:

$$
G_{u}=G_{d} .
$$

Gassmann's (1951) theory (Equations 8 and 9) can be extended to porous rocks saturated with multiple fluids (Mavko \& Mukerji, 1998). At low enough frequencies there is enough time for the fluids to flow and equilibration to occur at a constant pressure. The rock can therefore be considered homogeneously saturated at such low frequencies. Consequently, the bulk moduli of the saturating fluids can be used to describe a single phase effective fluid bulk modulus by applying Wood's (1955) law:

$$
K_{f}=\left(\frac{S_{\mathrm{CO}_{2}}}{K_{\mathrm{CO}_{2}}}+\frac{S_{w}}{K_{w}}\right)^{-1}
$$

where $S$ and $K$ refer to the saturation and bulk modulus, respectively. The subscribes $f, \mathrm{CO}_{2}$ and $w$ refer to the effective single-phase fluid, carbon dioxide and water, respectively. As only $\mathrm{CO}_{2}$ and water saturate the sample, $S_{\mathrm{CO}_{2}}+S_{w}=1$. The effective fluid bulk modulus $K_{f}$ can then be used as an input in Equation 8 to determine the low frequency or Gassmann-Wood limit of an undrained sample saturated with two fluids.

At high frequencies there is not enough time for the fluids to flow and pressure to equilibrate. The separate fluid phases are effectively isolated such that Equation 8 can be used to define an undrained bulk modulus for each region saturated by the respective fluid. Subsequently an effective bulk modulus for the entire sample can be defined by applying Hill's (1963) law:

$$
K_{G H}=\left(\frac{S_{\mathrm{CO}_{2}}}{K_{u-\mathrm{CO}_{2}}+4 / 3 G_{d}}+\frac{S_{w}}{K_{u-w}+4 / 3 G_{d}}\right)^{-1}-\frac{4}{3} G_{d},
$$

where $\mathrm{K}_{u-\mathrm{CO}_{2}}$ and $\mathrm{K}_{u-w}$ are the undrained bulk modulus of the portions of the sample saturated only by $\mathrm{CO}_{2}$ and water, respectively (Mavko \& Mukerji, 1998). This high frequency limit will be referred to as the Gassmann-Hill limit. From the underlying assumption that the sample behaves mechanically isotropic a Young's modulus can be determined form the derived bulk and shear moduli. In Figure 5, we see that both the measured Young's and Bulk moduli converge approximately to the Gassmann-Wood limit at low frequencies and to the Gassman-Hill limit at high frequencies.

The procedure used to induce the exsolution of $\mathrm{CO}_{2}$ during this experiment is essentially the same as for the experiments that produced the fluid distribution shown in Figure 4, with the exception of a higher pressure decline rate. As a first order approximation such a fluid distribution is analogous to that of White et al.'s (1975) 1D interlayer flow model, which consists of periodically alternating layers of fluids. White et al.'s (1975) analytical solution does not account for the impact of the membrane between the $\mathrm{CO}_{2}$ and water, which on the one hand can reduce attenuation by FPD when the pressure discontinuity inhibits pressure diffusion (Qi et al., 2014a, 2014b; Tserkovnyak \& Johnson, 2003) and on the other can be a significant source dissipation if the membrane slides or deforms (Miskis, 1988; Moerig et al., 1996; Rozhko \& Bauer, 2018). Given that we have a very low $\mathrm{CO}_{2}$ saturation during the experiment and the membrane stiffness between the fluid phases in a Berea sandstone can be considered very low (Nagy \& Blaho, 1994), the impact of capillary effects is likely negligible (Pride et al., 2004; Rozhko \& Bauer, 2018). Included in Figure 5 is the result of the analytical solution of the interlayer flow model (e.g., Quintal et al., 2009), where the water saturated layer constitutes $99.5 \%$ of the sample length and the $\mathrm{CO}_{2}$ saturated layer constitutes $0.5 \%$ of the sample length. The mean attenuation measured in the fully water saturated sample $\left(Q_{E}^{-1} \sim 0.011\right.$ and $Q_{K}^{-1} \sim$ 0.007) is added to the result of the analytical solution (Tisato \& Quintal, 2014) and the physical properties of the solid frame of the sample and the saturating fluids can be found in Tables 2 and 3. Even though the interlayer flow model is only a first order approximation of the fluid distribution, the analytical solution matches fairly well the frequency-dependent attenuation and modulus dispersion. 
Table 2

Physical Properties of the Solid Frame

\begin{tabular}{lcc}
\hline Symbol & Property & BSP4 \\
\hline$K_{s}$ & Bulk modulus of the solid matrix (GPa) & $30^{\mathrm{a}}$ \\
$\phi$ & Porosity (\%) & 19.6 \\
$k$ & Permeability (mD) & 270 \\
$K_{d}$ & Bulk modulus of the drained frame (GPa) & 11.7 \\
$G$ & Shear modulus of the drained frame (GPa) & 11.1 \\
\hline${ }^{2}$ Tarokh and Makhnenko (2019).
\end{tabular}

\subsubsection{Depressurization-Hydrostatic}

Figure 6 shows the volumetric strain measured during the hydrostatic depressurization experiments Exs-3 and Exs-4. During the experiments there is no record of the fluid pressure because the micro-valves in the sample holder are closed. The volumetric strain is determined from the axial and radial strains as $\epsilon_{\mathrm{vol}}=\epsilon_{\mathrm{ax}}+2 \epsilon_{\mathrm{rad}}$, where a negative volumetric strain corresponds to an expansion of the sample. During Exs-3 the response of the volumetric strain is similar to the fluid pressure response during experiment Exs-2 and remains constant approximately $2 \mathrm{~h}$ after initiating depressurization. During Exs-4 the volumetric strain increases linearly, with the increase in the slope after $2 \mathrm{~h}$ suggesting the onset of $\mathrm{CO}_{2}$ exsolution. From the volumetric strain we determine a $\mathrm{CO}_{2}$ saturation of approximately $0.1 \%$. Details on how the $\mathrm{CO}_{2}$ saturation was determined from the volumetric strain can be found in Appendix B.

Figure 7 shows shows the results of three forced oscillation measurements taken between 2 and $7.3 \mathrm{~h}$ after initiating depressurization, during experiment Exs-3. Frequency dependent attenuation and modulus dispersion are observed in the extensional (Figures $7 \mathrm{a}$ and $7 \mathrm{~d}$ ) and bulk (Figures $7 \mathrm{~b}$ and $7 \mathrm{e}$ ) deformation modes, with a possible attenuation peak above $500 \mathrm{~Hz}$. The shear modulus and attenuation are approximately frequency independent and show a small artifact around $1 \mathrm{~Hz}$ (Figures 7c and 7f). The dispersive portions of the Young's and bulk moduli are partly below the theoretical high and low frequency limits. With respect to time, a small reduction in the Young's and bulk moduli is observed. The small shift in the attenuation peak, with respect to experiment Exs-2, may be explained by the method of depressurization used. By hydrostatically reducing the confining pressure on the sample it is likely that exsolution of $\mathrm{CO}_{2}$ took place preferentially along all of the samples surfaces and not just at one outlet as was the case in experiments Exs-8b, Exs-9, and Exs-10b. A consequence of such a fluid distribution would be a shortening of the length scale over which fluid pressure diffusion occurs and a shift of the attenuation peak to higher frequencies as compared to experiment Exs-2. Such a shift in frequency can be understood in terms of the characteristic frequency, which is inversely proportional to the square of the length scale of the fluid heterogeneity (e.g., Dutta \& Seriff, 1979). In addition, considering the very low $\mathrm{CO}_{2}$ saturation, the presence of some $\mathrm{CO}_{2}$ in the remaining volume of the pore fluid lines may contribute to making the sample partially drained (Pimienta et al., 2016), possibly explaining why at low frequencies the measured bulk and Young's modulus are below the Gassmann-Wood limit.

Figure 8 shows the results of two forced oscillation measurements taken at 5 and $6.1 \mathrm{~h}$ after initiating depressurization, during experiment Exs-4. Again, frequency-dependent attenuation and modulus dispersion are observed in the extensional (Figures $8 \mathrm{a}$ and $8 \mathrm{~d}$ ) and bulk (Figures $8 \mathrm{~b}$ and 8e) deformation modes. The attenuation is lower compared to Exs-3, with a possible attenuation peak at an even higher frequency compared to Exs-2 and Exs-3. The shear modulus and attenuation are frequency independent (Figures 8c and 8f). The much lower pressure decline rate likely allowed for a more homogenous distribution of $\mathrm{CO}_{2}$ throughout the sample which would further reduce the length scale over which fluid pressure diffusion occurs and consequently result in a shift of the attenuation peak to higher frequencies. However, again the presence of $\mathrm{CO}_{2}$ in the remaining volume of the fluid lines could explain why the Young's and bulk modulus at low frequencies are lower than the Gassmann-Wood limit. After the experiment the pore and confining pressures were increased to 5 and $15 \mathrm{MPa}$ respectively, $3 \mathrm{~h}$ later we performed another forced oscillation measurement under undrained conditions. The sample is now significantly stiffer, as demonstrated by the elevated Young's and Bulk moduli. The shear modulus is approximately unchanged and the attenuation in all three modes is negligible and approximately frequency independent. The undrained data set is also included in Figure 1a (Appendix A). 

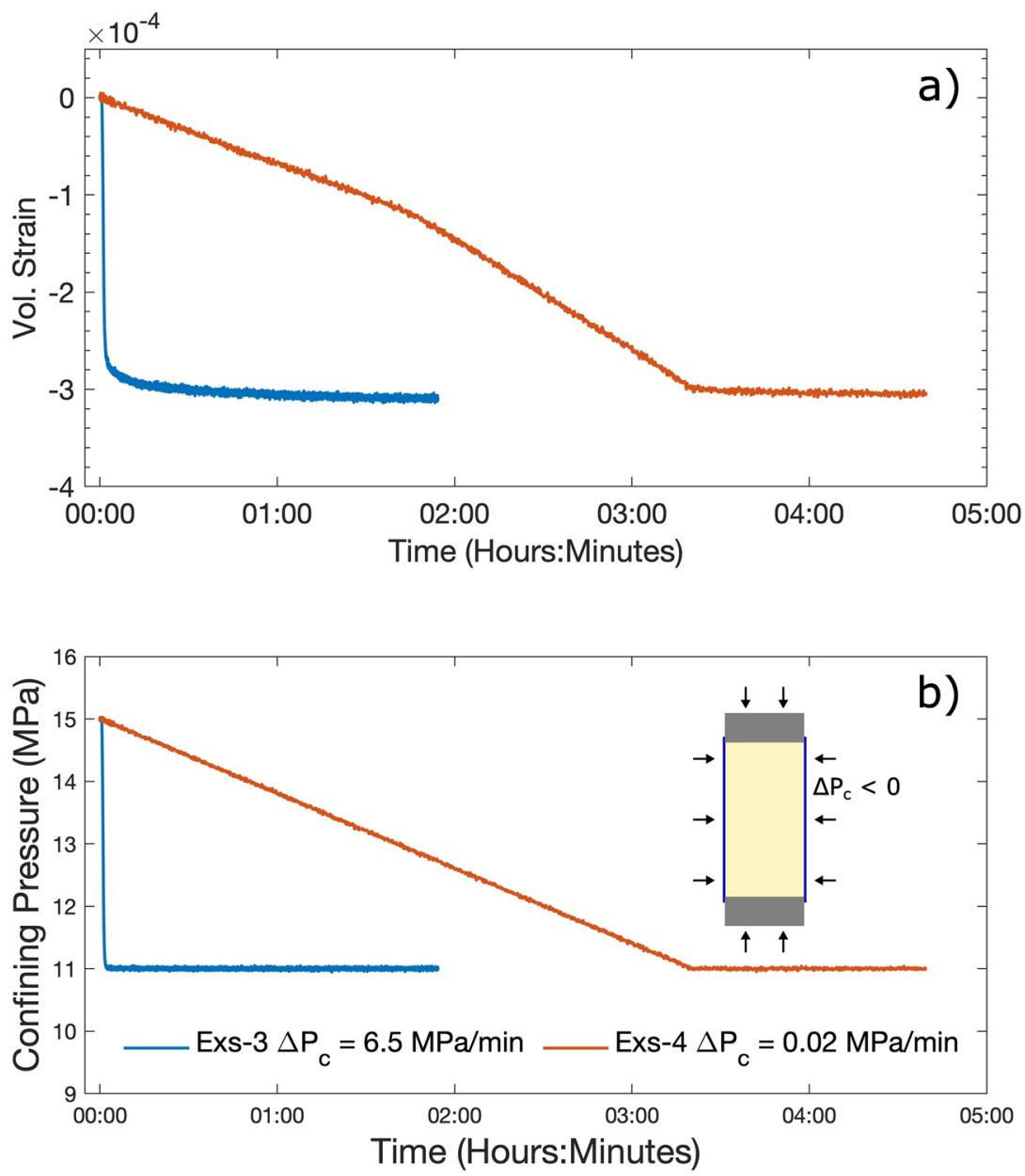

Figure 6. (a) Volumetric strain measured during the hydrostatic depressurization experiments Exs-3 and Exs-4. The confining pressure (b) was lowered from 15 to $11 \mathrm{MPa}$ at a rate of 6.5 and $0.02 \mathrm{MPa}$ per minute for Exs-3 and Exs-4, respectively. The micro-valves in the sample holders were closed making the sample effectively undrained, as illustrated in the inset.

\section{Numerical Modeling of Attenuation and Dispersion}

\subsection{Mathematical Formulation and Numerical Solution}

To model the attenuation and modulus dispersion caused by fluid pressure diffusion at the mesoscopic scale, we solve Biot's (1941) quasi-static equations of poroelasticity in the displacement-pressure (u-p) formulation (Quintal et al., 2011). In the frequency domain, these equations are formulated in the following way:

$$
\begin{gathered}
\nabla \cdot \boldsymbol{\sigma}=0 \\
\nabla \cdot\left(-\frac{k}{\eta} \nabla p\right)+\alpha \nabla \cdot(I \omega \boldsymbol{u})+\frac{I \omega p}{M}=0,
\end{gathered}
$$

where $p, I$, and $\omega$ are the fluid pressure, the imaginary unit, and the angular frequency, respectively. The solid displacement vector $\boldsymbol{u}$ has the components $u_{i}$ in the $i$-th directions, where $i=x, y, z$. The total stress tensor $\sigma$ has the components (Biot, 1941):

$$
\sigma_{i j}=2 \mu \epsilon_{i j}+\lambda e \delta_{i j}-\alpha p \delta_{i j}
$$



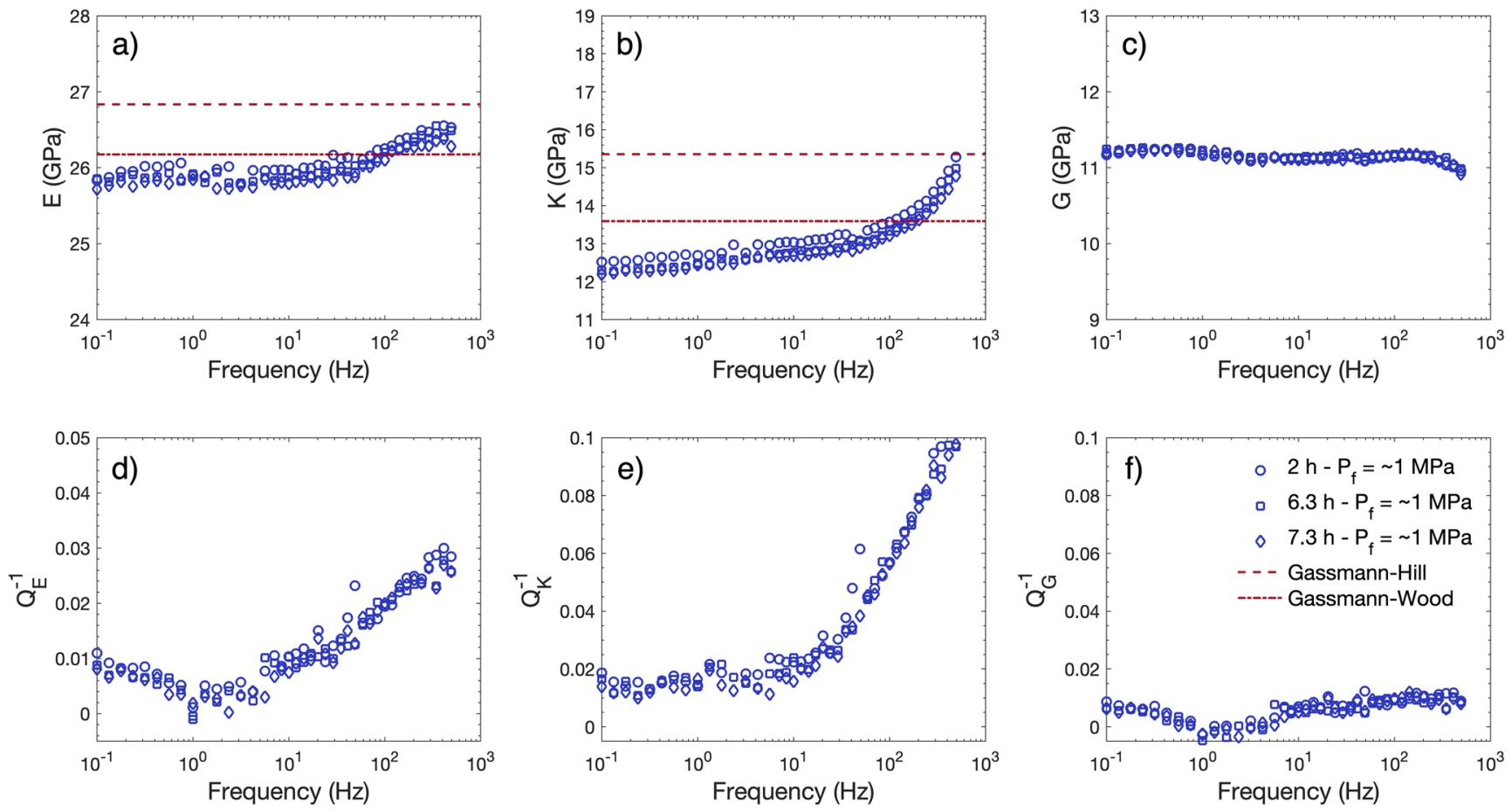

Figure 7. (a) Young's $E$, (b) Bulk $K$, and (c) Shear $G$ modulus and the corresponding attenuation (d) $Q_{E}^{-1}$, (e) $Q_{K}^{-1}$, and (f) $Q_{G}^{-1}$ from experiment Exs-3 measured at a differential pressure of approximately $10 \mathrm{MPa}$ and approximately $0.1 \% \mathrm{CO}_{2}$ saturation. The legend shows the time at which each measurement was taken after the initiation of depressurization, as well as the theoretical high and low frequency limits.
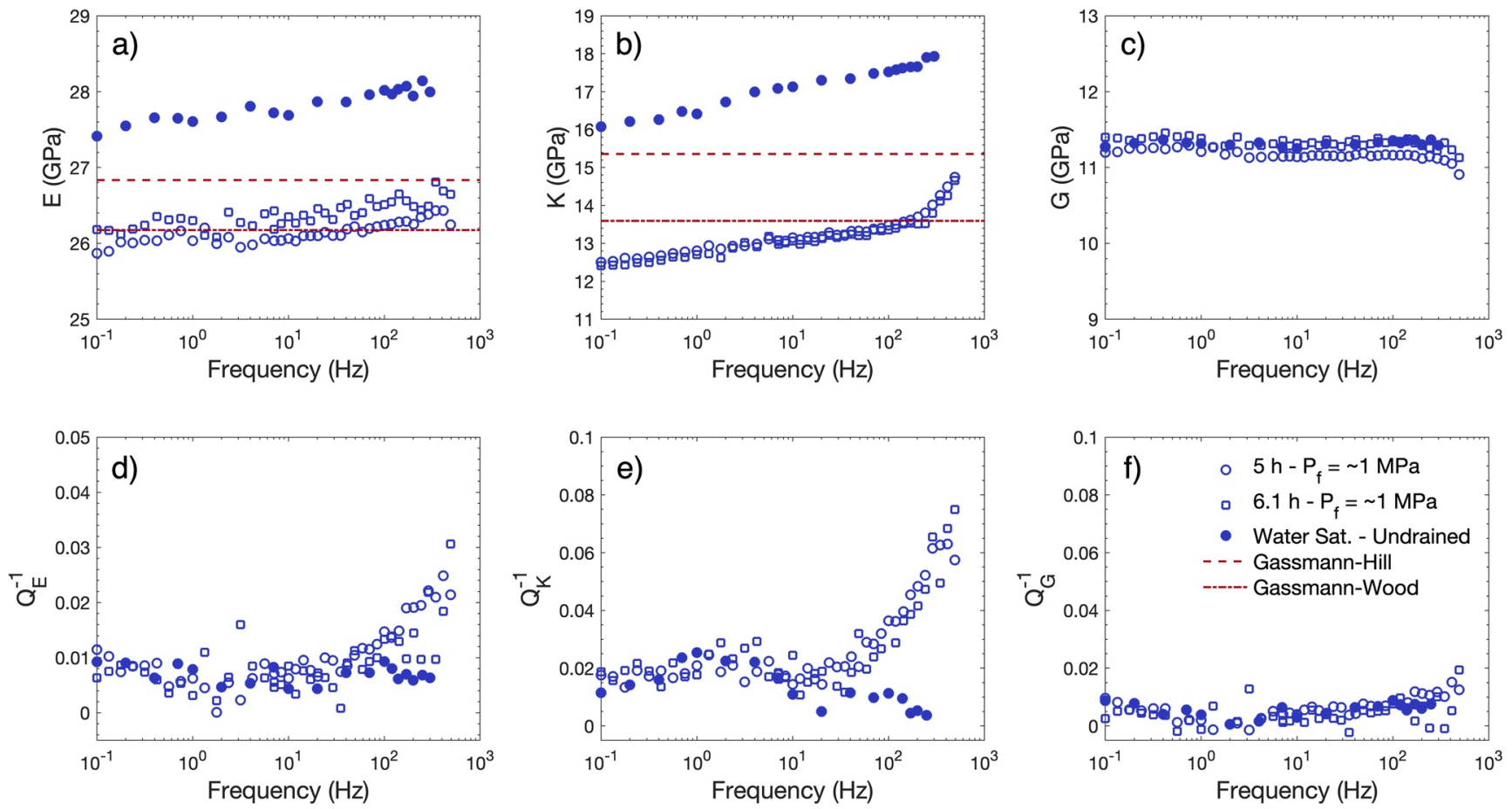

Figure 8. (a) Young's $E$, (b) Bulk $K$, and (c) Shear $G$ modulus and the corresponding attenuation (d) $Q_{E}^{-1}$, (e) $Q_{K}^{-1}$, and (f) $Q_{G}^{-1}$ from experiment Exs-4 measured at an approximately $0.1 \% \mathrm{CO}_{2}$ saturation. Included is also a measurement of the water saturated sample under undrained conditions conducted at a pore pressure of $5 \mathrm{MPa}, 3 \mathrm{~h}$ after completing experiment Exs-4. All measurements were performed at a differential pressure of approximately $10 \mathrm{MPa}$. The legend shows the time at which each measurement was taken after the initiation of depressurization, as well as the theoretical high and low frequency limits. 
where $\delta_{i j}$ and $\varepsilon_{i j}$ are the Kronecker delta and the components of the strain tensor, respectively. The cubical dilatation $e$ is given by the trace of the strain tensor. The mechanical material properties of the porous frame are given by Lamé's parameters $G$ and $\lambda$, with $\lambda=K-2 G / 3$, where $G$ and $K$ are the shear and bulk modulus of the drained frame, respectively. The coefficients $\alpha$ and $M$ (Biot \& Willis, 1957) are defined as:

$$
\begin{gathered}
\alpha=1-\frac{K_{d}}{K_{s}} \text { and, } \\
M=\left(\frac{\phi}{K_{f}}+\frac{\alpha-\phi}{K_{s}}\right)^{-1},
\end{gathered}
$$

where $K_{s}$ and $K_{f}$ are again the bulk modulus of the the solid matrix and the saturating fluid, respectively. The remaining material properties of the frame and saturating fluid to be accounted for are: the porosity $\phi$, permeability $k$, and viscosity $\eta$.

Equations 12 and 13 are solved in the Mathematics module of COMSOL Multiphysics, which uses the finite element method. The numerical model has by default undrained boundary conditions, meaning there is no fluid flow across the boundary and corresponds to the experimental conditions during the forced oscillation measurements. Alternatively, a drained boundary condition can be implemented by setting the fluid pressure at the boundary to zero. Uniaxial compression tests are simulated on 2D rectangular models, with the same dimensions as the sample BSP4. A homogenous time-harmonic oscillatory displacement is applied to the top model boundary, while a zero displacement boundary condition is applied in the horizontal direction on the lateral boundary and in the vertical direction on the bottom boundary (Chapman \& Quintal, 2018). With this boundary condition configuration a frequency-dependent complex P-wave modulus can be determined form the spatial average of the vertical stress and strain. The associated attenuation is derived from the ratio between the imaginary and real parts of the the complex modulus (O'Connell \& Budiansky, 1978). For the isotropic models it is then trivial to obtain the Young's and bulk moduli from the P-wave and shear moduli, allowing for a comparison with the forced oscillation measurements. The shear modulus in our problem is real valued and independent of frequency, it is simply determined from Gassmann's (1951) relations (Equation 9).

Our numerical implementation was validated by comparing the numerical solutions to analytical solutions for the drained-undrained transition (Pimienta et al., 2016) and the interlayer flow model (White et al., 1975), as shown by Chapman and Quintal (2018). In the numerical simulation we average the vertical stress and strain over the whole sample, to obtain the global response, and, alternatively, a single slice of $6 \mathrm{~mm}$ thickness placed at the center of the model to represent the local response measured by the strain gauges (Figure 9). A broader discussion of the impact of locally averaged stress and strain can be found in Chapman and Quintal (2018).

\subsection{Utilisation of Fluid Distribution From Medical X-Ray CT}

The interlayer flow model served as a good initial approximation of the fluid distribution in the sample (Figure 4) and of the measured frequency-dependent attenuation and dispersion (Figure 6). To more accurately model the measured attenuation and dispersion, the $\mathrm{CO}_{2}$ saturation distribution determined from the X-ray CT scans can be used as an input for our numerical approach, to define a single phase effective fluid. For the fluid bulk modulus we again use Wood's (1955) law (Equation 10). The effective fluid viscosity is described by Teja and Rice (1981) as:

$$
\eta_{f}=\eta_{\mathrm{CO}_{2}}\left(\frac{\eta_{w}}{\eta_{\mathrm{CO}_{2}}}\right)^{S_{w}}
$$

where $\eta_{\mathrm{CO}_{2}}$ and $\eta_{w}$ are the viscosity of $\mathrm{CO}_{2}$ and water, respectively. $S_{w}$ is again the water saturation, such that $\mathrm{S}_{\mathrm{CO}_{2}}+S_{w}=1$. The porosity derived from the X-ray CT could also be used as an input in the numerical approach, however, because the sample is structurally quite homogenous (Figure 2) this is not necessary 

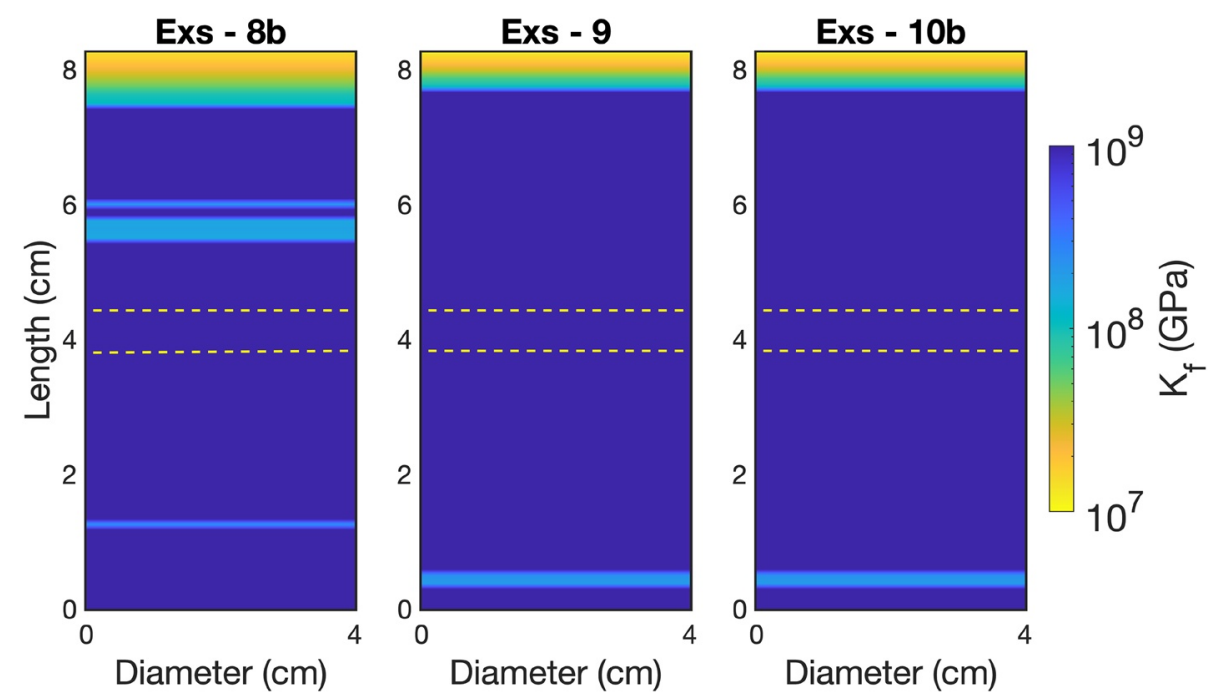

Figure 9. Effective fluid bulk modulus $K_{f}$ distributions used in the numerical models. The distributions are derived from the slice averaged $\mathrm{CO}_{2}$ saturation profiles of experiments Exs-8b, Exs-9, and Exs-10b (Figure 4), resulting in a 1D

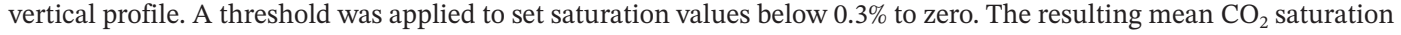
over the whole model domain is $0.36 \%$ for Exs-8b and $0.28 \%$ for Exs-9 and Exs-10b. The dashed yellow lines indicate the region of $6 \mathrm{~mm}$ thickness over which the stress and strain responses are averaged to represent a local measurement similar to the strain gauges used in the forced oscillation experiments.

at this point. Therefore, the properties of the solid frame are constant throughout the model with only the fluid properties varying spatially. The physical properties for the solid frame of the model and the saturating fluids can be found in Tables 2 and 3 .

As an input we utilize the slice averaged $\mathrm{CO}_{2}$ saturation and not the 3D distribution from experiments Exs8b, Exs-9, and Exs-10 (Figure 4), which means the numerical simulations use effectively 1D models. There are two reasons for utilizing the slice averages: (i) the overall $\mathrm{CO}_{2}$ saturation in the sample is low, and (ii) the uncertainty in the $\mathrm{CO}_{2}$ saturation at the voxel scale relatively high. The low overall saturation means that at the voxel scale the saturation ranges predominantly between $5 \%$ and $15 \%$ (Figure 4). Such a range of saturations along with an uncertainty in saturation of $\pm 3.6 \%$ at the voxel scale translates into an order of magnitude variation in the bulk modulus of the effective fluid (Equation 10). The low overall saturation also means that many voxels have negative saturation values, requiring an appropriate threshold below which the $\mathrm{CO}_{2}$ saturation is set to zero. Both of these factors strongly impact the variation in the effective fluid properties and its distribution, which produces a large variation in the numerical result. To minimize the variation in the numerical solution we decided to use the slice averages instead. A saturation of $0.3 \%$ was chosen as a threshold below which the $\mathrm{CO}_{2}$ saturation is set to zero. The threshold corresponds to twice the uncertainty in saturation for the slice averages. By applying the threshold the mean saturation in the model is reduced slightly with respect to the experiments. Figure 9 shows the resulting fluid bulk modulus $K_{f}$ distributions used as an input for the numerical model.

\subsection{Numerical Simulation Results}

We first investigate how choosing the threshold impacts the numerical solutions for the frequency dependent attenuation and modulus dispersion. Two thresholds, $0.15 \%$ and $0.3 \%$, were applied to the $\mathrm{CO}_{2}$ saturation values derived from the X-ray CT scans of experiment Exs-8b, which had a more homogenous distribution of $\mathrm{CO}_{2}$ along the length of the sample than the other two experiments. Figure 10 shows the numerical results for the frequency dependent Young's (Figure 10a) and bulk modulus (Figure 10b), along with the corresponding attenuation (Figures 10c and 10d). By applying a more conservative threshold of $0.3 \%$ the overall attenuation and moduli dispersion is significantly increased, with the attenuation peak at approximately $100 \mathrm{~Hz}$ increased by approximately 50\%. The increase in the attenuation is explained by the fact 

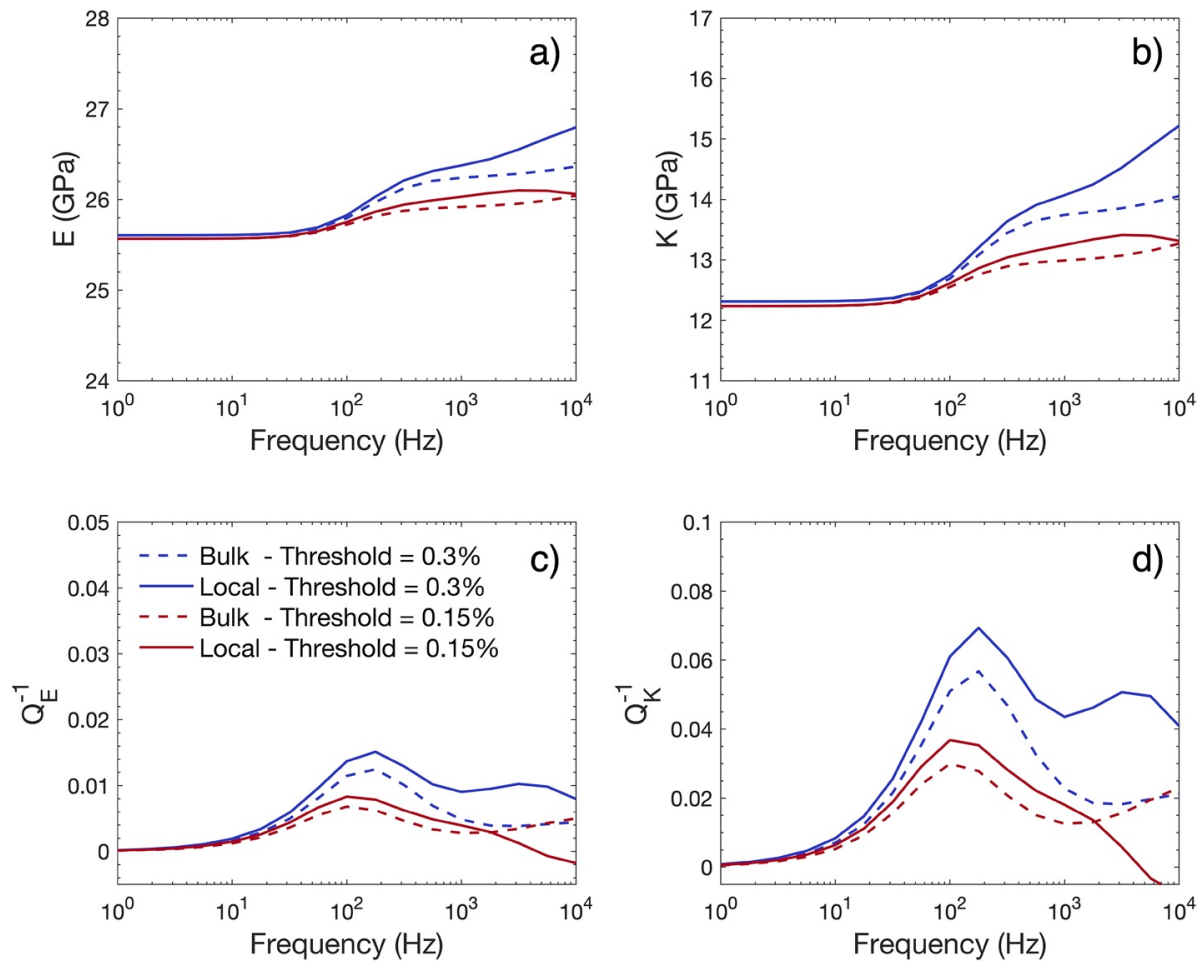

Figure 10. (a) Young's $E$ and (b) Bulk $K$ modulus and the corresponding attenuation (c) $Q_{E}^{-1}$ and (d) $Q_{K}^{-1}$ from the numerical simulation with undrained boundary conditions and utilizing the fluid distribution derived from the slice averages of experiment Exs- $8 \mathrm{~b}$. A threshold of $0.15 \%$ and $0.3 \%$ were considered below which the $\mathrm{CO}_{2} \mathrm{saturation}$ was set to zero. For both cases the global and local response of the sample are considered.

that applying a higher threshold increases the heterogeneity of the fluid distribution, which increases the contrast in the fluid compressibility near the outlet compared to the rest of the sample. Besides the choice of threshold, the locally derived attenuation and dispersion also deviates from that determined from the whole sample, and in the case of the $0.3 \%$ threshold a second attenuation peak appears at approximately $5 \mathrm{kHz}$. The choice of threshold had no impact on the numerical results for experiment Exs-9 and only negligible impact for experiment Exs-10b.

Figure 11 shows the numerical results for the fluid distributions from experiments Exs-9 and Exs-10b (Figure 9), as well as the forced oscillation measurements from experiment Exs-2. As was the case with the analytical solution for the interlayer flow model (Figure 5) the attenuation measured in the fully water saturated sample was added to the numerical result. The difference in the distribution of $\mathrm{CO}_{2}$ for Exs-9 and Exs-10b is minimal and only produces a small variation in attenuation and dispersion, that is within the uncertainty of the forced oscillation measurement. It is important to remember, however, that the forced oscillation measurements and X-Ray CT where not performed concurrently. The experiments where conducted at slightly different temperatures and pressure decline rates. Given the comparable total saturation and pressure conditions (Figure 3) we expect the fluid distribution observed in Exs-9 and Exs-10b to closely resemble the distribution in Exs-2. In the extensional mode (Figures 11a and 11c) the numerical results from the local responses match well the measured attenuation, both in terms of the amplitude and characteristic frequency, as well as the dispersion in Young's modulus. The discrepancy in the bulk modulus and the corresponding attenuation (Figures $11 \mathrm{~b}$ and $11 \mathrm{~d}$ ) could be attributed to the inherent anisotropy in the samples mechanical properties. Overall, the numerical results present a significant improvement in interpreting the forced oscillation data, in comparison to the analytical solution of the interlayer flow model (Figure 5).

In experiments Exs-3 (Figure 7) and Exs-4 (Figure 8) the Gassmann-Wood limit was higher than the Young's and bulk modulus measured at low frequencies. A possible explanation was that the presence of $\mathrm{CO}_{2}$ in the remaining volume of the connected fluid lines relaxes the undrained boundary condition, because the 

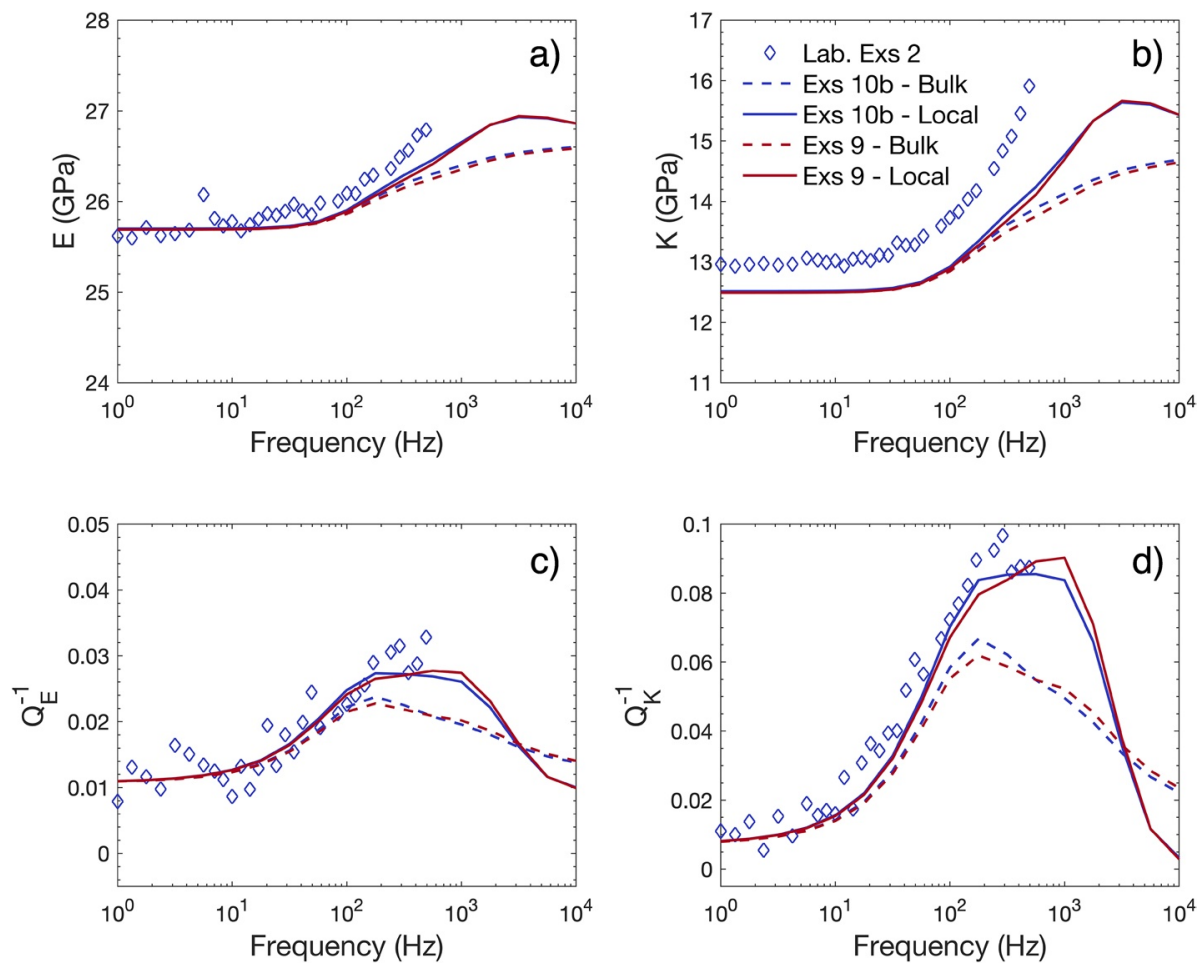

Figure 11. (a) Young's $E$ and (b) Bulk $K$ modulus and the corresponding attenuation (c) $Q_{E}^{-1}$ and (d) $Q_{K}^{-1}$ measured in experiment Exs-2 and the numerical simulations having undrained boundary conditions and utilizing the fluid distributions derived from the slice averages of experiments Exs-9 and Exs-10b. For the fluid distribution a threshold of $0.3 \%$ was applied to the slice averages below which the $\mathrm{CO}_{2}$ saturation was set to zero. For both cases the global and local response of the sample are considered.

high compressibility of the gas increases the storage capacity of the remaining dead volume (Pimienta et al., 2016). To investigate the impact of a drained boundary condition on the numerical simulations we set the fluid pressure to zero at the top our model. The top boundary is chosen because most of the exsolved $\mathrm{CO}_{2}$ is located at that boundary. Figure 12 shows the results from the drained and undrained simulations utilizing the fluid distribution from experiment Exs-9 (Figure 9). At low frequencies the Young's and bulk modulus are lower for the drained simulation as would be expected, which results in a greater dispersion of the moduli and an overall increase in the corresponding attenuation. A partially drained boundary condition would result in low frequency moduli that fall between the cases with drained and undrained boundary conditions. The impact of a partially drained boundary condition would be expected to diminish in experiments conducted at higher pressure because of the reduced compressibility of the gas.

\section{Discussion}

The experiments performed in our study are comparable in terms of the degree of gas saturation as well as the pressure and temperature conditions to those performed by Tisato et al. (2015) and Chapman et al. (2017). The experimental procedure was significantly improved upon, by closely controlling the rate of pressure decline and gas saturation. Furthermore it was possible to measure both the axial and radial deformation on the sample, allowing for investigating the bulk and shear deformation modes of the sample. However, we were not able to reproduce the observations of Tisato et al. (2015) and Chapman et al. (2017), which observed significant frequency-dependent attenuation and dispersion in the frequency range of 1-10 $\mathrm{Hz}$ and attributed it to the exsolution and dissolution of pore scale bubbles. The mentioned studies assumed a homogenous distribution of pore scale gas bubbles which is not consistent with our observations (Figure 4).

The observed attenuation and dispersion in the partially saturated sample in this study is explained well by FPD at the mesoscopic scale. However, the heterogenous fluid distribution along the length of the sample 

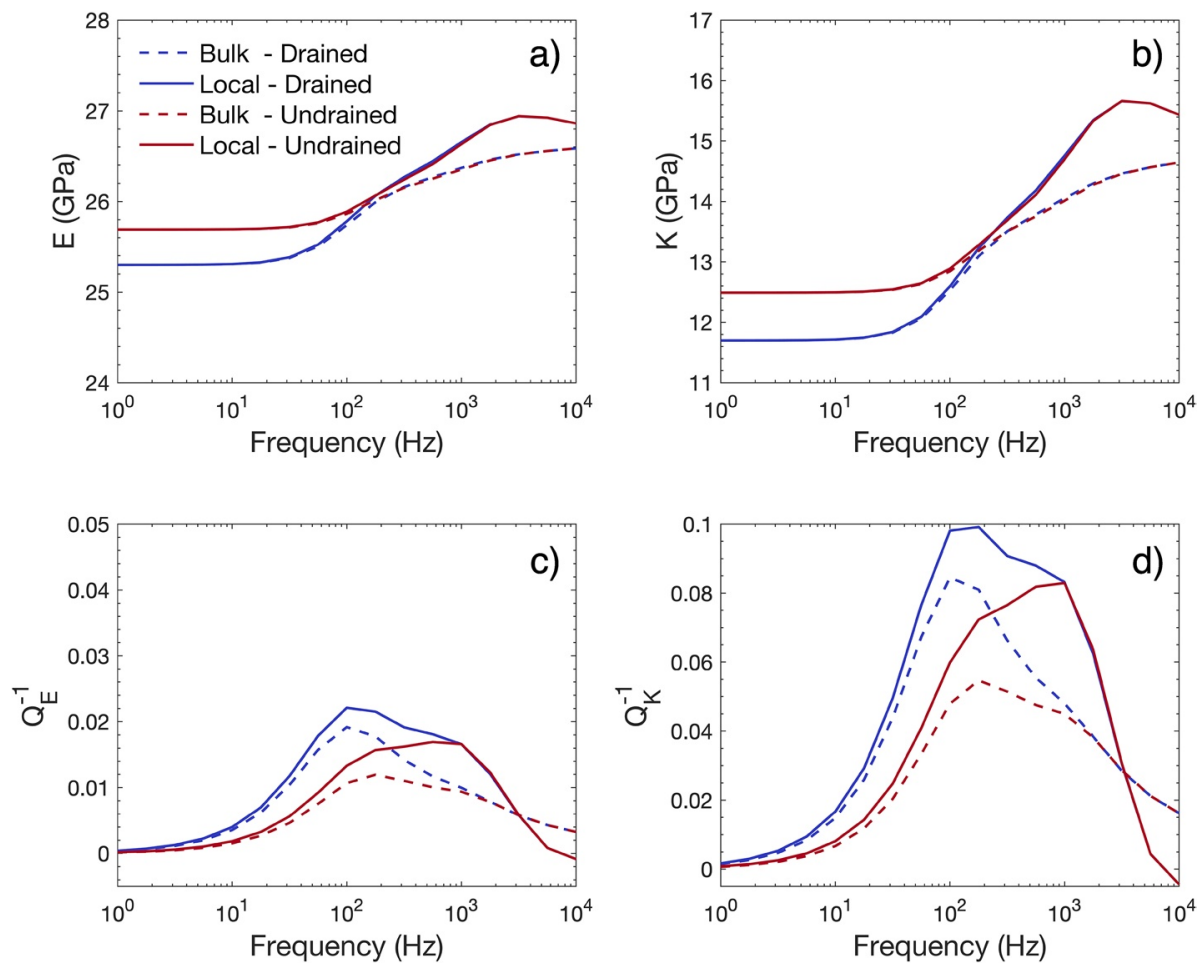

Figure 12. (a) Young's $E$ and (b) Bulk $K$ modulus and the corresponding attenuation (c) $Q_{E}^{-1}$ and (d) $Q_{K}^{-1}$ from the drained and undrained numerical simulations utilizing the fluid distributions derived from the slice averages of experiment Exs-9. For the drained simulation the fluid pressure was set to zero at the top model boundary. A threshold of $0.3 \%$ was applied to the slice averages below which the $\mathrm{CO}_{2}$ saturation was set to zero. For both cases the global and local response of the sample are considered.

in response to a rapid depressurization and subsequent exsolution of $\mathrm{CO}_{2}$ means that the measured frequency-dependent attenuation and modulus dispersion are unique to the sample geometry. Such a dependence on the sample geometry were previously observed by Tisato and Quintal (2013) and Chapman et al. (2016), where water was introduced into the samples by imbibition, as well as by Spencer and Shine (2016) who injected a small layer of supercritical $\mathrm{CO}_{2}$ into the top of their sample. By using the observed fluid distribution form the X-ray CT as an input for the numerical modeling of FPD we were able to quantitatively assess the observed attenuation and dispersion. Further developing our approach could allow for establishing accurate relationships between fluid saturation, as well as distribution, and the frequency-dependent attenuation and dispersion of seismic waves.

The next steps to be taken should be the inclusion of the 3D fluid distribution, as well as other properties that can be derived from X-ray CT, such as subcore-scale porosity and permeability. As seen in Figure 10, the threshold below which saturation levels are set to zero can strongly impact the numerical result. Similarly, at the voxel scale a sensitivity analysis should be performed to asses how the variation in the uncertainty of saturation with voxel size impacts the numerical output. In the numerical simulations presented here, the porosity and permeability were kept constant over the entire model domain, equivalent to the mean porosity and permeability measured in the sample. For the given fluid distribution, where FPD was taking place over the bulk of the sample, and the relative homogeneity of the sample, such a simplification was appropriate. However, in drainage and imbibition scenarios where the fluid distribution is governed by variations in subcore-scale porosity and permeability, such an approximation will no longer be appropriate. Particularly, subcore-scale variations in permeability, which can be significant even in Berea sandstone (Pini \& Benson, 2017), are expected to play an important role in controlling the characteristic frequencies at which the attenuation of seismic waves is significant (Kobayashi \& Mavko, 2016; Rubino et al., 2013). Core-flooding experiments with concurrent X-ray CT and measurements of capillary pressure can accurately determine 
the sub-core scale permeability distributions by utilizing an iterative method based on the Leverett-J capillary pressure scaling relationship (Krause \& Benson, 2015; Krause et al., 2013). Experimental verification may however require the development of new experimental setups. There are examples of setups capable of measuring dynamic mechanical properties of samples concurrently with X-ray CT. However, where this is possible the range of frequencies over which the measurements can be performed is narrow (e.g., Nakagawa et al., 2013) or the samples are small (e.g., Tisato et al., 2016), making both multiphase core flooding experiments and measurements of the dynamic mechanical properties susceptible to boundary condition effects.

\section{Conclusions}

We presented the results of experiments on a Berea sandstone sample investigating the fluid distribution and the frequency dependent attenuation and modulus dispersion following depressurization and the subsequent exsolution of $\mathrm{CO}_{2}$. In a first set of experiments the fluid distribution was characterized with X-ray CT at the millimeter scale, showing a heterogenous distribution of fluids along the length of the sample following rapid depressurization. In a separate experimental set-up, following a similar depressurization protocol we observed significant frequency-dependent attenuation and dispersion in the Young's and bulk moduli. These observations are consistent with fluid pressure diffusion at the mesoscopic scale resulting from the large contrast in compressibility between the water and $\mathrm{CO}_{2}$. We also observe a dependence of attenuation and dispersion on the rate of fluid pressure decline, suggesting that a slow pressure decline results in more a homogenous distribution of the $\mathrm{CO}_{2}$ and a shift of the attenuation peak to higher frequencies. A workflow is presented to use the $\mathrm{CO}_{2}$ saturation distribution derived from the X-ray CT scans as a direct input for the numerical simulations of attenuation and modulus dispersion by fluid pressure diffusion. The results of the numerical simulation improve the fit to the measured attenuation and dispersion compared to that of a simple analytical solution. Our numerical simulations are also used to assess the impact of the experimental configuration, such as boundary conditions and local measurements of strain. Furthermore, the workflow can be easily extended to include other sub-core scale properties that can be derived form X-ray CT, such as spatial distributions of porosity and permeability. An extension of this workflow could allow for accurate relationships between fluid saturation and the attenuation of seismic waves to be derived for drainage and imbibition scenarios, which could improve the monitoring of $\mathrm{CO}_{2}$ storage operations by making it possible to assess the effectiveness of residual trapping by the formation.

\section{Appendix A: Forced Oscillation-Dry and Water Saturated}

In this section, we present the forced oscillation measurements performed on the dry and water saturated sample, at a differential pressure of $10 \mathrm{MPa}$. The dry sample was subjected to a confining pressure of $10 \mathrm{MPa}$, while for the water saturated sample the pore pressure was $5 \mathrm{MPa}$ and the confining pressure was $15 \mathrm{MPa}$. For the measurements under drained conditions, two syringe pumps, with a total volume of approximately $400 \mathrm{ml}$, were connected to the tri-axial cell and the micro-valves in the sample holders left open. With the micro-valves closed the remaining volume in the fluid lines is reduced to approximately 30 micro liters. The ratio between the remaining volume in the fluid lines and the pore volume is approximately $1 \times 10^{-3}$.

Figure A1 shows the elastic moduli and attenuation as a function of frequency. The elastic moduli measured in the dry sample are frequency independent between 0.1 and $500 \mathrm{~Hz}$. The attenuation is negligible, with the exception for a small resonance at approximately $1 \mathrm{~Hz}$. When the sample is water saturated and micro-valves in the sample holder are kept open the Young's (Figure A1a) and Bulk (Figure A1b) moduli are highly dispersive due to the transition from the drained to undrained regime, a result of fluid pressure diffusion out of the sample (Pimienta et al., 2016), for frequencies above $10 \mathrm{~Hz}$. What is unexpected is that the shear modulus (Figure A1c) also exhibits small but not negligible dispersion in response to the transition from drained to undrained conditions. Associated with the dispersion in the three moduli is frequency dependent attenuation. In the transition from drained to undrained conditions there is a strong resonance resulting most likely from the o-rings in the mirco-valves oscillating in the fluid pressure field, which may explain the dispersion in the shear modulus. When the valves are closed, both the moduli and attenuation are once again predominantly frequency independent. The Young's and shear modulus 

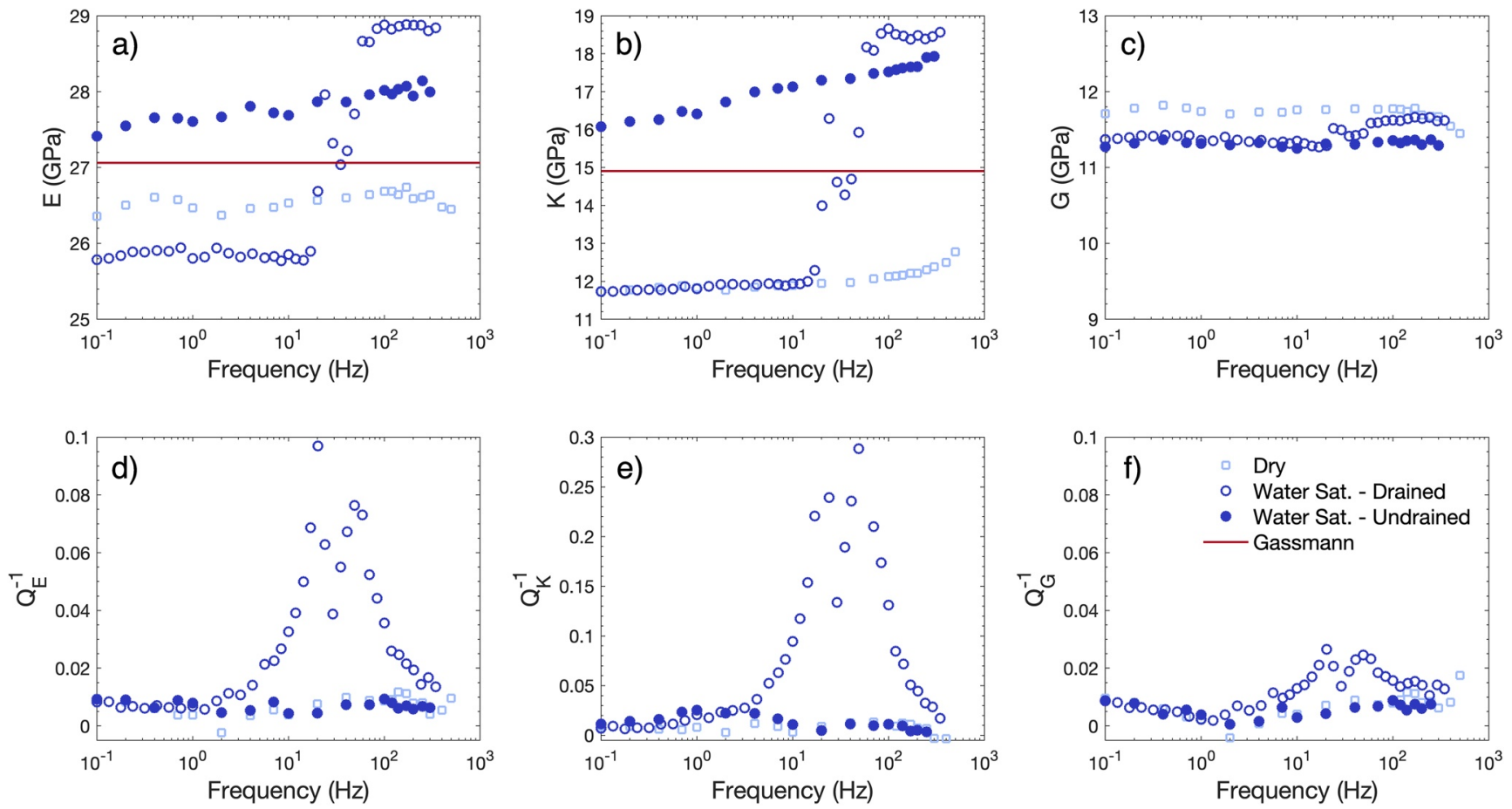

Figure A1. (a) Young's $E$, (b) Bulk $K$, and (c) Shear $G$ modulus and the corresponding attenuation (d) $Q_{E}^{-1}$, (e) $Q_{K}^{-1}$, and (f) $Q_{G}^{-1}$. The measurements were performed on the dry and water saturated, under drained and undrained conditions, at a differential pressure of $10 \mathrm{MPa}$. Gassmann's (1951) prediction for an undrained and water saturated sample is derived from the bulk and shear modulus measured in the drained sample.

measured in the drained sample are reduced with respect to the dry sample indicating a weakening of the sample due to the introduction of water, a common observation in sandstone (e.g., Chapman et al., 2016; Yin et al., 2019).

We utilize as inputs for Equations 8 and 9 the bulk and shear modulus measured in the drained sample, the average of measurements taken at less than $10 \mathrm{~Hz}$, and a grain bulk modulus of $30 \mathrm{GPa}$. Gassmann's equations assume that there is no chemical alteration of the solid matrix of the porous material by the fluids (e.g., Berryman, 1999), to negate the effect of introducing the water we utilize the measurements from the drained sample instead of the dry sample. From the underlying assumption that the sample behaves mechanically isotropic a Young's modulus can be determined form the derived bulk and shear moduli. As seen in Figure A1 the theoretical values for the Young's (Figure A1a) and Bulk (Figure A1b) modulus overall agree well with the moduli measured in the sample when the valves in the sample holder are closed, demonstrating the sample is indeed experimentally undrained.

\section{Appendix B: Determining $\mathrm{CO}_{2}$ Saturation}

The hydrostatic decompression during experiments Exs-3 and Exs-4 result in the volumetric expansion of the sample. Assuming the poroelastic properties of the sample remain approximately constant we can utilize the variation in stress and volumetric strain to infer the $\mathrm{CO}_{2}$ saturation. The problem is separated into two parts: (1) a first stage where the sample is undrained and fully water saturated and (2) a second stage where $\mathrm{CO}_{2}$ exsolution takes place.

For the first stage the pore pressure varies with confining pressure as (Skempton, 1954):

$$
\Delta P_{p}^{1}=B \Delta P_{c},
$$


where $P_{p}$ and $P_{c}$ are pore pressure and confining pressure, respectively. $B$ is the Skempton coefficient, which can be expressed in terms of the drained and undrained bulk moduli of the sample, $K_{u}$ and $K_{d}$ respectively, as:

$$
B=\frac{K_{u}-K_{d}}{\alpha K_{u}},
$$

where $\alpha$ is again the Biot-Willis coefficient (Equation 15). The change in volumetric strain on the sample under undrained conditions is defined as:

$$
\Delta \epsilon_{v}^{1}=-\frac{\Delta P_{c}}{K_{u}} .
$$

The variation in pore volume is related to the volumetric expansion of the saturating water as:

$$
\Delta V_{\phi}^{1}=V_{\phi}^{1}-V_{\phi}^{0}=-\frac{\Delta P_{p}^{1}}{K_{w}} V_{\phi}^{0},
$$

where $V_{\phi}^{0}$ and $V_{\phi}^{1}$ are the initial and intermediate pore volumes and $K_{w}$ is the water bulk modulus. Lastly, using Equation B1, B2 and B4 we can solve for the intermediate pore volume as:

$$
V_{\phi}^{1}=\left(1-\frac{K_{u}-K_{d}}{\alpha K_{u}} \cdot \frac{\Delta P_{c}}{K_{w}}\right) \phi^{0} V^{0},
$$

where $\phi^{0}$ and $V 0$ are the initial porosity and total volume of the sample, with $\phi^{0}=V_{\phi}^{0} / V^{0}$.

During the second stage the confining pressure remains constant while the exsolution of $\mathrm{CO}_{2}$ results in a rebound in the pore pressure. The variation in volumetric strain can be approximated as the variation in pore volume as (e.g., Wang, 2000):

$$
\Delta \epsilon_{v}^{2}=\frac{\alpha}{K_{d}} \Delta P_{p}^{2} \approx \frac{\Delta V_{\phi}^{2}}{V_{\phi}^{1}},
$$

where $\Delta V_{\phi}^{2}=V_{\phi}^{2}-V_{\phi}^{1}$, with $V_{\phi}^{2}=V_{C O_{2}}+V_{w}$. Using the same approach as in B4 the variation in pore pressure can be described as:

$$
\Delta P_{p}^{2}=P_{p}^{2}-P_{p}^{1}=-K_{w} \frac{V_{w}-V_{\phi}^{1}}{V_{\phi}^{1}},
$$

The total change in volumetric strain measured during the experiments is composed of the sum of the volumetric strain the the two parts of the problem as:

$$
\Delta \epsilon_{v}=\Delta \epsilon_{v}^{1}+\Delta \epsilon_{v}^{2} .
$$

The next step is to solve for the volume of $\mathrm{CO}_{2}$ that has come out of solution using Equation $\mathrm{B} 6$ and B7:

$$
\begin{gathered}
V_{\mathrm{CO}_{2}}=V_{\phi}^{2}-V_{w} \\
V_{\mathrm{CO}_{2}}=\left(1+\Delta \epsilon_{v}^{2}\right) V_{\phi}^{1}-\left(1-\frac{K_{d}}{\alpha K_{w}} \Delta \epsilon_{v}^{2}\right) V_{\phi}^{1}=\left(1+\frac{K_{d}}{\alpha K_{w}}\right) \Delta \epsilon_{v}^{2} V_{\phi}^{1} .
\end{gathered}
$$

We can now finalize the expression for the volume of $\mathrm{CO}_{2}$ in terms of the measured volumetric strain and confining pressure by using Equation B3, B5 and B8: 


$$
V_{\mathrm{CO}_{2}}=\left(1+\frac{K_{d}}{\alpha K_{w}}\right)\left(\Delta \epsilon_{v}+\frac{\Delta P_{c}}{K_{u}}\right)\left(1-\frac{K_{u}-K_{d}}{\alpha K_{u}} \frac{\Delta P_{c}}{K_{w}}\right) \phi_{0} V_{0}
$$

The final volume of water in the sample is:

$$
V_{w}=\left(1-\frac{K_{d}}{\alpha K_{w}}\left(\Delta \epsilon_{v}+\frac{\Delta P_{c}}{K_{u}}\right)\right)\left(1-\frac{K_{u}-K_{d}}{\alpha K_{u}} \frac{\Delta P_{c}}{K_{w}}\right) \phi_{0} V_{0}
$$

From Equation $\mathrm{B} 10$ and $\mathrm{B} 11$ the $\mathrm{CO}_{2}$ saturation as:

$$
S_{\mathrm{CO}_{2}}=\frac{V_{\mathrm{CO}_{2}}}{V_{\mathrm{CO}_{2}}+V_{w}}
$$

Using Equation $\mathrm{B} 12$ a $\mathrm{CO}_{2}$ saturation of $\sim 0.1 \%$ was determined, which was in close agreement with the pore volume change measured with the Quizix pump for a similar change in differential pressure when the sample was water saturated.

\section{Data Availability Statement}

Datasets for this research are available in the data citation references Chapman et al. (2020) or by following the link: https://doi.org/10.5281/zenodo.4401884.

\begin{abstract}
Acknowledgments
This work was supported by an Early Postdoc.Mobility Fellowship (project no. P2LAP2_181260) from the Swiss National Science Foundation. The experimental work was partially supported by the Region Ile-de-France in the framework of DIM Oxymore, by CNRS via "Mission pour les Initiatives Transverses et Interdisciplinaires” (MITI) and "Cellule Energie" of CNRS through the project "LAB- $4 \mathrm{D}$ ". The work was also supported by the Global Climate and Energy Project at Stanford. S. C. would also like to thank Maartje Boon, Charlotte Garing and Chris Zahasky for fruitful discussions and support with the experiments using the X-ray CT and data processing. Special thanks also go to Editor Douglas Schmitt and the three reviewers, particularly Nicola Tisato and Qiaomu Qi, for their valuable comments and suggestions that substantially improved the manuscript.
\end{abstract}

\section{References}

Akin, S., \& Kovscek, A. R. (2003). Computed Tomography in Petroleum Engineering Research (Vol. 215, pp. 23-38). Geological Society London, Special Publications. https://doi.org/10.1144/GSL.SP.2003.215.01.03

Alemu, B. L., Aker, E., Soldal, M., Johnsen, Ø., \& Aagaard, P. (2013). Effect of sub-core scale heterogeneities on acoustic and electrical properties of a reservoir rock: $\mathrm{A} \mathrm{CO}_{2}$ flooding experiment of brine saturated sandstone in a computed tomography scanner. Geophysical Prospecting, 61, 235-250. https://doi.org/10.1111/j.1365-2478.2012.01061.x

Allman, B. P., \& Shearer, P. M. (2007). Spatial and temporal stress drop variations in small earthquakes near Parkfield, California. Journal of Geophysical Research, 112. B04305. https://doi.org/10.1029/2006JB004395

Arora, P., \& Kovscek, A. R. (2003). A mechanistic modeling and experimental study of solution gas drive. Transport in Porous Media, 51, 237-265. https://doi.org/10.1023/a:1022353925107

Batzle, M. L., Han, D.-H., \& Hofmann, R. (2006). Fluid mobility and frequency-dependent seismic velocity - Direct measurements. Geophysics, 71, N1-N9. https://doi.org/10.1190/1.2159053

Benson, S. M., \& Cole, D. R. (2008). CO2 Sequestration in deep sedimentary formations. Elements, 4, 325-331. https://doi.org/10.2113/ gselements.4.5.325

Berryman, J. G. (1999). Origin of Gassmann's equations. Geophysics, 64, 1627-1629. https://doi.org/10.1190/1.1444667

Biot, M. A. (1941). General theory of three-dimensional consolidation. Journal of Applied Physics, 12, 155-164. https://doi. org/10.1063/1.1712886

Biot, M. A. (1962). Mechanics of deformation and acoustic propagation in porous media. Journal of Applied Physics, 33, 1482-1498. https:// doi.org/10.1063/1.1728759

Biot, M. A., \& Willis, D. G. (1957). The elastic coefficients of the theory of consolidation. Journal of Applied Mechanics, 24, 594-601.

Blanchard, T. D., \& Delommot, P. (2015). An example of the measurement and practical applications of time-lapse seismic attenuation. Geophysics, 80, WA25-WA34. https://doi.org/10.1190/geo2014-0186.1

Borgomano, J. V. M., Gallagher, A., Sun, C., \& Fortin, J. (2020). An apparatus to measure elastic dispersion and attenuation using hydrostaticand axial-stress oscillations under undrained conditions. Review of Scientific Instruments, 91, 034502. https://doi.org/10.1063/1.5136329

Borgomano, J. V. M., Pimienta, L., Fortin, J., \& Gueguen, Y. (2017). Dispersion and attenuation measurements of elastic moduli of a dual-porosity limestone. Journal of Geophysical Research: Solid Earth, 122. https://doi.org/10.1002/2016JB013816

Cadoret, T., Marion, D., \& Zinszner, B. (1995). Influence of frequency and fluid distribution on elastic wave velocities in partially saturated limestones. Journal of Geophysical Research: Solid Earth, 100(B6), 9789-9803. https://doi.org/10.1029/95jb00757

Cadoret, T., Mavko, G., \& Zinszner, B. (1998). Fluid distribution effect on sonic attenuation in partially saturated limestones. Geophysics, 63, 154-160. https://doi.org/10.1190/1.1444308

Carcione, J. M., Helle, H. B., \& Pham, N. H. (2003). White's model for wave propagation in partially saturated rocks: Comparison with poroelastic numerical experiments. Geophysics, 68, 1389-1398.

Caspari, E., Müller, T. M., \& Gurevich, B. (2011). Time-lapse sonic logs reveal patchy CO2 saturation in-situ. Geophysical Research Letters, 38, a. L13301. https://doi.org/10.1029/2011GL046959

Chapman, S., Borgomano, J. V. M., Quintal, B., Benson, S. M., \& Fortin, J. (2020). Experimental Data for "Seismic attenuation and dispersion due to partial fluid saturation: Direct measurements and numerical simulations based on X-Ray CT. [Data set]. Zenodo https://doi. org/10.5281/zenodo.4401884

Chapman, S., Borgomano, J. V. M., Yin, H., Fortin, J., \& Quintal, B. (2019). Forced oscillation measurements of seismic wave attenuation and stiffness moduli dispersion in glycerine-saturated Berea sandstone. Geophysical Prospecting, 67, 956-968. https://doi. $\operatorname{org} / 10.1111 / 1365-2478.12710$ 
Chapman, S., \& Quintal, B. (2018). Numerical analysis of local strain measurements in fluid-saturated rock samples submitted to forced oscillations. Geophysics, 83, MR309-MR316. https://doi.org/10.1190/geo2018-0071.1

Chapman, S., Quintal, B., Tisato, N., \& Holliger, K. (2017). Frequency scaling of seismic attenuation in rocks saturated with two fluid phases. Geophysical Journal International, 208, 221-225. https://doi.org/10.1093/gji/ggw387

Chapman, S., Tisato, N., Quintal, B., \& Holliger, K. (2016). Seismic attenuation in partially saturated Berea sandstone submitted to a range of confining pressures. Journal of Geophysical Research: Solid Earth, 121, 1664-1676. https://doi.org/10.1002/2015JB012575

Crews, J. B., \& Cooper, C. A. (2014). Transient pore pressure response to confining stress excursions in Berea sandstone flooded with an aqueous solution of CO2. Water Resources Research, 50, 4775-4786. https://doi.org/10.1002/2014WR015305

Duan, Z., \& Sun, R. (2003). An improved model calculating CO2 solubility in pure water and aqueous $\mathrm{NaCl}$ solutions from 273 to $533 \mathrm{~K}$ and from 0 to 2000 bar. Chemical Geology, 193, 257-271. https://doi.org/10.1016/s0009-2541(02)00263-2

Dutta, N. C., \& Seriff, A. J. (1979). On White's model of attenuation in rocks with partial gas saturation. Geophysics, 44, $1806-1812$.

Falahat, R., Obidegwu, D., Shams, A., \& MacBeth, C. (2014). the interpretation of amplitude changes in 4d seismic data arising from gas exsolution and dissolution. Petroleum Geoscience, 20, 303-320. https://doi.org/10.1144/petgeo2014-008

Gassmann, F. (1951). Über die Elastizität poröser Medien. Vierteljahrsschrift der Naturforschenden Gesellschaft in Zürich, 96, 1-23.

Goertz-Allmann, B. P., Goertz, A., \& Wiemer, S. (2011). Stress drop variations of induced earthquakes at the Basel geothermal site. Geophysical Research Letters, 38, L09308. https://doi.org/10.1029/2011GL047498

Hill, R. (1963). Elastic properties of reinforced solids: Some theoretical principles. Journal of the Mechanics and Physics of Solids, 11, 357-372. https://doi.org/10.1016/0022-5096(63)90036-x

Ivanova, A., Kashubin, A., Juhojuntti, N., Kummerow, J., Henninges, J., Juhlin, C., et al. (2012). Monitoring and volumetric estimation of injected CO 2 using 4D seismic, petrophysical data, core measurements and well logging: A case study at Ketzin, Germany. Geophysical Prospecting, 60, 957-973. https://doi.org/10.1111/j.1365-2478.2012.01045.x

Johnson, D. L. (2001). Theory of frequency dependent acoustics in patchy-saturated porous media. Journal of the Acoustical Society of America, 110(2), 682-694. https://doi.org/10.1121/1.1381021

Johnston, D. H., \& Toksöz, M. N. (1980). UltrasonicPandSwave attenuation in dry and saturated rocks under pressure. Journal of Geophysical Research, 85, 925-936. https://doi.org/10.1029/jb085ib02p00925

Kareem, R., Cubillas, P., Gluyas, J., Bowen, L., Hillier, S., \& Greenwell, H. C. (2017). Multi-technique approach to the petrophysical characterization of Berea sandstone core plugs (Cleveland Quarries, USA). Journal of Petroleum Science and Engineering, 149, 436-455. https://doi.org/10.1016/j.petrol.2016.09.029

Kobayashi, Y., \& Mavko, G. (2016). Variation in P-wave modulus with frequency and water saturation: Extension of dynamic-equivalent-medium approach. Geophysics, 81, D479-D494. https://doi.org/10.1190/geo2015-0045.1

Krause, M., Krevor, S., \& Benson, S. M. (2013). A procedure for the accurate determination of sub-core scale permeability distributions with error quantification. Transport in Porous Media, 98, 565-588. https://doi.org/10.1007/s11242-013-0161-y

Krause, M. H., Benson, S. M. (2015). Accurate determination of characteristic relative permeability curves. Advances in Water Resources, 83, 376-388. https://doi.org/10.1016/j.advwatres.2015.07.009

Krevor, S. C. M., Pini, R., Zuo, L., \& Benson, S. M. (2012). Relative permeability and trapping of CO2 and water in sandstone rocks at reservoir conditions. Water Resources Research, 48, W02532. https://doi.org/10.1029/2011WR010859

Li, X., \& Yortsos, Y.C. (1995). Visualization and simulation of bubble growth in pore networks. AIChE J, 41, 214-222. https://doi. org/10.1002/aic.690410203

Lopes, S., \& Lebedev, M. (2012). Research note: Laboratory study of the influence of changing the injection rate on the geometry of the fluid front and on P-wave ultrasonic velocities in sandstone. Geophysical Prospecting, 60, 572-580. https://doi. org/10.1111/j.1365-2478.2011.01009.x

Lopes, S., Lebedev, M., Müller, T. M., Clennell, M. B., \& Gurevich, B. (2014). Forced imbibition into a limestone: Measuring P-wave velocity and water saturation dependence on injection rate. Geophysical Prospecting, 62, 1126-1142. https://doi.org/10.1111/1365-2478.12111

Lucet, N., Rasolofosaon, P. N. J., \& Zinszner, B. (1991). Sonic properties of rocks under confining pressure using the resonant bar technique. Journal of the Acoustical Society of America, 89, 980-990. https://doi.org/10.1121/1.400643

Luhmann, A. J., Kong, X.-Z., Tutolo, B. M., Ding, K., Saar, M. O., \& Seyfried, W. E., Jr (2012). Permeability reduction produced by grain reorganization and accumulation of exsolved $\mathrm{CO} 2$ during geologic carbon sequestration: A new $\mathrm{CO} 2$ Trapping mechanism. Environmental Science \& Technology, 47, 242-251. https://doi.org/10.1021/es3031209

Masson, Y. J., \& Pride, S. R. (2007). Poroelastic finite difference modeling of seismic attenuation and dispersion due to mesoscopic-scale heterogeneity. Journal of Geophysical Research, 112, B03204. https://doi.org/10.1029/2006JB004592

Mavko, G., \& Mukerji, T. (1998). Bounds on low-frequency seismic velocities in partially saturated rocks. Geophysics, 63, 918-924. https:// doi.org/10.1190/1.1444402

McKavanagh, B., \& Stacey, F. D. (1974). Mechanical hysteresis in rocks at low strain amplitudes and seismic frequencies. Physics of the Earth and Planetary Interiors, 8, 246-250. https://doi.org/10.1016/0031-9201(74)90091-0

Miskis, M. J. (1988). Effects of contact line movement on the dissipation of waves in partially saturated rocks. Journal of Geophysical Research, 93, 6624-6634.

Moerig, R., Waite, W. F., Boyd, O. S., Getting, I. C., \& Spetzler, H. A. (1996). Seismic attenuation in artificial glass cracks: Physical and physicochemical effects of fluids. Geophysical Research Letters, 23, 2053-2056. https://doi.org/10.1029/96gl02147

Müller, T. M., Gurevich, B., \& Lebedev, M. (2010). Seismic wave attenuation and dispersion resulting from wave-induced flow in porous rocks - A review. Geophysics, 75, A147-A164

Murphy, W. F. (1982). Effects of partial water saturation on attenuation in Massilon sandstone and Vycor porous glass. Journal of the Acoustical Society of America, 71(6), 1458-1468. https://doi.org/10.1121/1.387843

Nagy, P. B., \& Blaho, G. (1994). Experimental measurements of surface stiffness on water-saturated porous solids. Journal of the Acoustical Society of America, 95, 828-835. https://doi.org/10.1121/1.408393

Nakagawa, S. (2011). Split Hopkinson resonant bar test for sonic-frequency acoustic velocity and attenuation measurements of small, isotropic geological samples. Review of Scientific Instruments, 82, 044901. https://doi.org/10.1063/1.3579501

Nakagawa, S. (2013). Low-frequency $(<100 \mathrm{~Hz})$ dynamic fracture compliance measurement in the laboratory, 47th US Rock Mechanics/ Geomechanics Symposium. ARMA, 13-343.

Nakagawa, S., Kneafsey, T. J., Daley, T. M., Freifeld, B. M., \& Rees, E. V. (2013). Laboratory seismic monitoring of supercritical CO2flooding in sandstone cores using the Split Hopkinson Resonant Bar technique with concurrent x-ray computed tomography imaging. Geophysical Prospecting, 61, 254-269. https://doi.org/10.1111/1365-2478.12027

O'Connell, J. R., \& Budiansky, B. (1978). Measures of dissipation in viscoelastic media. Geophysical Research Letters, 5, 5-8. 
Pimienta, L., Borgomano, J. V. M., Fortin, J., \& Guéguen, Y. (2016). Modeling the drained/undrained transition: Effect of the measuring method and the boundary conditions. Geophysical Prospecting, 64, 1098-1111. https://doi.org/10.1111/1365-2478.12390

Pini, R., \& Benson, S. M. (2017). Capillary pressure heterogeneity and hysteresis for the supercritical CO2/water system in a sandstone. Advances in Water Resources, 108, 277-292. https://doi.org/10.1016/j.advwatres.2017.08.011

Pini, R., Krevor, S. C. M., \& Benson, S. M. (2012). Capillary pressure and heterogeneity for the CO2/water system in sandstone rocks at reservoir conditions. Advances in Water Resources, 38, 48-59. https://doi.org/10.1016/j.advwatres.2011.12.007

Pride, S. R., Berryman, J. G., \& Harris, J. M. (2004). Seismic attenuation due to wave-induced flow. Journal of Geophysical Research, 109, B01201. https://doi.org/10.1029/2003JB002639

Qi, Q., Müller, T. M., Gurevich, B., Lopes, S., Lebedev, M., \& Caspari, E. (2014). Quantifying the effect of capillarity on attenuation and dispersion in patchy-saturated rocks. Geophysics, 79, WB35-WB50. https://doi.org/10.1190/geo2013-0425.1

Qi, Q., Müller, T. M., \& Rubino, J. G. (2014b). Seismic attenuation: Effects of interfacial impedance on wave-induced pressure diffusion. Geophysical Journal International, 199, 1677-1681. https://doi.org/10.1093/gii/ggu327

Quintal, B., Schmalholz, S. M., \& Podladchikov, Y. Y. (2009). Low-frequency reflections from a thin layer with high attenuation caused by interlayer flow. Geophysics, 74(1), N15-N23. https://doi.org/10.1190/1.302662010.1190/1.3184800

Quintal, B., Steeb, H., Frehner, M., \& Schmalholz, S. M. (2011). Quasi-static finite element modeling of seismic attenuation and dispersion due to wave-induced fluid flow in poroelastic media. Journal of Geophysical Research, 116, B01201. https://doi.org/10.1029/2010JB007475

Rozhko, A. Y., \& Bauer, A. (2018). Contact line friction and surface tension effects on seismic attenuation and effective bulk moduli in rock with a partially saturated crack. Geophysical Prospecting, 67, 913-934. https://doi.org/10.1111/1365-2478.12653

Rubino, J. G., Monachesi, L. B., Müller, T. M., Gurracino, L., \& Holliger, K. (2013). Seismic wave attenuation and dispersion due to wave-induced fluid flow in rocks with strong permeability fluctuations. Journal of the Acoustical Society of America, 134, 4742-4751.

Rubino, J. G., Ravazzoli, C. L., \& Santos, J. E. (2009). Equivalent viscoelastic solids for heterogeneous fluid-saturated porous rocks. Geophysics, 74, N1-N13. https://doi.org/10.1190/1.3008544

Skempton, A. W. (1954). The pore-pressure coefficients A and B. Géotechnique, 4, 143-147. https://doi.org/10.1680/geot.1954.4.4.143

Spencer, J. W., Jr (1981). Stress relaxations at low frequencies in fluid-saturated rocks: Attenuation and modulus dispersion. Journal of Geophysical Research, 86, 1803-1812. https://doi.org/10.1029/jb086ib03p01803

Spencer, J. W., \& Shine, J. (2016). Seismic wave attenuation and modulus dispersion in sandstones. Geophysics, 81, D211-D231. https:// doi.org/10.1190/geo2015-0342.1

Stabile, T. A., Satriano, C., Orefice, A., Festa, G., \& Zollo, A. (2012). Anatomy of a microearthquake sequence on an active normal fault. Scientific Reports, 2, 410. https://doi.org/10.1038/srep00410

Tarokh, A., \& Makhnenko, R. Y. (2019). Remarks on the solid and bulk responses on fluid-filled porous rock. Geophysics, 84, $1942-2156$. https://doi.org/10.1190/geo2018-0495.1. https://doi.org/10.1190/geo2018-0495.1

Teja, A. S., \& Rice, P. (1981). Generalized corresponding states method for the viscosities of liquid mixtures. Industrial \& Engineering Chemistry Fundamentals, 20(1), 77-81. https://doi.org/10.1021/i100001a015

Tisato, N., \& Madonna, C. (2012). Attenuation at low seismic frequencies in partially saturated rocks: Measurements and description of a new apparatus. Journal of Applied Geophysics, 86, 44-53. https://doi.org/10.1016/j.jappgeo.2012.07.008

Tisato, N., \& Quintal, B. (2013). Measurements of seismic attenuation and transient fluid pressure in partially saturated Berea sandstone: Evidence of fluid flow on the mesoscopic scale. Geophysical Journal International, 195, 342-351. https://doi.org/10.1093/gji/ggt259

Tisato, N., \& Quintal, B. (2014). Laboratory measurements of seismic attenuation in sandstone: Strain versus fluid saturation effects. Geophysics, 79, WB9-WB14. https://doi.org/10.1190/geo2013-0419.1

Tisato, N., Quintal, B., Chapman, S., Podladchikov, Y., \& Burg, J. P. (2015). Bubbles attenuate elastic waves at seismic frequencies: First experimental evidence. Geophysical Research Letters, 42, 3880-3887. https://doi.org/10.1002/2015GL063538

Tisato, N., Zhao, Q., \& Grasselli, G. (2016). Experimental rock physics under micro-CT (pp. 3251-3255). SEG Technical Program Expanded Abstracts.

Toksöz, M. N., Johnston, D. H., \& Timur, A. (1979). Attenuation of seismic waves in dry and saturated rocks: I. Laboratory measurements. Geophysics, 44(4), 681-690. https://doi.org/10.1190/1.1440969

Toms, J., Müller, T. M., \& Gurevich, B. (2007). Seismic attenuation in porous rocks with random patchy saturation. Geophysical Prospecting, 55, 671-678. https://doi.org/10.1111/j.1365-2478.2007.00644.x

Toms-Stewart, J., Müller, T. M., Gurevich, B., \& Paterson, L. (2009). Statistical characterization of gas-patch distributions in partially saturated rocks. Geophysics, 74, WA51-WA64. https://doi.org/10.1190/1.3073007

Tserkovnyak, Y., \& Johnson, D. L. (2003). Capillary forces in the acoustics of patchy-saturated porous media. Journal of the Acoustical Society of America, 114, 2596-2606. https://doi.org/10.1121/1.1621009

Wang, H. F. (2000). Theory of linear poroelasticity with applications to geomechanics and hydrogeology. Princeton University Press.

White, J. E. (1975). Computed seismic speeds and attenuation in rocks with partial gas saturation. Geophysics, 40, 224-232. https://doi. org/10.1190/1.1440520

White, J. E., Mikhaylova, N. G., \& Lyakhovitskiy, F. M. (1975). Low-frequency seismic waves in fluid-saturated layered rocks. Earth Physics, 10, 654-659.

Winkler, K., \& Nur, A. (1979). Pore fluids and seismic attenuation in rocks. Geophysical Research Letters, 6(1), 1-4. https://doi.org/10.1029/ gl006i001p00001

Winkler, K. W., \& Plona, T. J. (1982). Technique for measuring ultrasonic velocity and attenuation spectra in rocks under pressure. Journal of Geophysical Research, 87(B13), 10776-10780. https://doi.org/10.1029/jb087ib13p10776

Wood, A. B. (1955). A textbook of sound. The MacMillan Company.

Woodford, O. (2020). vol3d v2. MATLAB Central File Exchange. Retrieved from https://www.mathworks.com/matlabcentral/ fileexchange/22940-vol3d-v2

Yin, H., Borgomano, J. V. M., Wang, S., Tiennot, M., Fortin, J., \& Gueguen, Y. (2019). Fluid substitution and shear weakening in clay-bearing sandstone and shear weakening in clay-bearing sandstone at seismic frequencies. Journal of Geophysical Research: Solid Earth, 124 . https://doi.org/10.1029/2018jb016241. https://doi.org/10.1029/2018JB016241

Zhang, Y., Nishizawa, O., Kiyama, T., \& Xue, Z. (2015). Saturation-path dependency of P-wave velocity and attenuation in sandstone saturated with $\mathrm{CO} 2$ and brine revealed by simultaneous measurements of waveforms and X-ray computed tomography images. Geophysics, 80, D403-D415. https://doi.org/10.1190/geo2014-0289.1

Zhu, T., Ajo-Franklin, J. B., \& Daley, T. M. (2017). Spatiotemporal changes of seismic attenuation caused by injected CO2at the Frio-II pilot site, Dayton, TX, USA. Journal of Geophysical Research: Solid Earth, 122, 7156-7171. https://doi.org/10.1002/2017JB014164 
Zuo, L., \& Benson, S. M. (2014). Process-dependent residual trapping of CO2 in sandstone. Geophysical Research Letters, 41, 2820-2826. https://doi.org/10.1002/2014GL059653

Zuo, L., Krevor, S., Falta, R. W., \& Benson, S. M. (2012). An Experimental study of CO2 exsolution and relative permeability measurements during CO2 saturated water depressurization. Transport in Porous Media, 91, 459-478. https://doi.org/10.1007/s11242-011-9854-2

Zuo, L., Zhang, C., Falta, R. W., \& Benson, S. M. (2013). Micromodel investigations of CO2 exsolution from carbonated water in sedimentary rocks. Advances in Water Resources, 53, 188-197. https://doi.org/10.1016/j.advwatres.2012.11.004 